\title{
A comparison of initial stiffness formulations for small-strain soil-pile dynamic Winkler modelling
}

Prendergast, L.J., ${ }^{\mathrm{a}, 1}$ Gavin, K. ${ }^{\mathrm{a}, 2}$

${ }^{a}$ School of Civil, Structural and Environmental Engineering, University College Dublin,

Newstead,

Belfield,

Dublin 4,

IRL

${ }^{1}$ Corresponding author

Phone: ${ }^{1}+353-1-7163231 /{ }^{2}+353-1-7163222$

Email: ${ }^{1}$ luke.prendergast@ucdconnect.ie, ${ }^{2}$ kenneth.gavin@ucd.ie.

\begin{abstract}
Dynamic Soil-Structure Interaction (DSSI) is an area of much ongoing research and has wide and varied applications from seismic response analysis to offshore wind foundation response. DSSI covers a wide range of load regimes from small-strain vibrations to large-strain cyclic loading. One of the most common ways to model DSSI uses the Winkler model, which considers the soil as a series of mutually independent springs. The difficulty with modelling DSSI arises with the inelastic and nonlinear load-displacement response of soil with increasing strain, therefore modelling of largestrain DSSI relies on the specification of many interrelated parameters. The relative magnitude of these parameters can have a significant effect on the modelled response. In this paper, the specification of an initial stiffness coefficient to model the elastic (small-strain) response of a soil-pile system is investigated. The coefficient of subgrade reaction method can be used to generate spring stiffness moduli for Winkler type models. A number of subgrade reaction theories have been proposed and their application to the problem of static loading has been widely studied. However, relatively little research concerning the application of these models for small-strain dynamic loading has been undertaken. This paper describes a sensitivity study in which a number of subgrade reaction models were used to estimate the frequency response at small-strain levels for a range of pile geometries and ground conditions. A field investigation was undertaken on two piles with different slenderness ratios to estimate the frequency response and damping ratios. The experimental results were compared to predictions of damped natural frequency obtained from numerical models using the force input and measured damping ratio from each experiment. The ability of each subgrade reaction formulation to model the response at small-strain levels is evaluated.
\end{abstract}

Keywords: Piles; Frequency; Modulus Subgrade Reaction; Dynamics; SHM 


\subsection{Introduction}

\subsection{Dynamic soil-structure interaction (DSSI)}

Dynamic Soil-Structure Interaction (DSSI) is a vital aspect of the design of many structures subjected to variable external excitation as part of their in service operation. The response of soil-pile systems to lateral loading is an area of growing research interest. The term 'dynamic' covers a broad spectrum of structural schemes ranging from large-strain cyclic loading to small-strain system vibrations. The response of a soil-pile system is heavily dependent on the nature and magnitude of the loading and a variety of modelling approaches exist that aim to predict the response of these systems under various load schemes. In particular, DSSI is an integral part in the design of offshore wind turbines, which experience periodic excitation from a combination of environmental loading (wind and wave action) and structural effects. The rotor spinning at a given rotational velocity creates an excitation force with a frequency termed the $1 \mathrm{P}$ frequency. For a standard, three-bladed, wind turbine, the blades passing the tower induce a second excitation force, the frequency of which is termed the 3P frequency. Waves typically affect wind turbines with excitation frequencies lower than the $1 \mathrm{P}$ band, (see Fig. 1). Flexible monopiles are often designed in such a manner as to ensure that the global system has a natural frequency between the $1 \mathrm{P}$ and $3 \mathrm{P}$ range and it is critical that a designer can accurately predict the system's natural frequency and avoid resonance [1,2]. However, recent field measurements suggest that the soil stiffness values recommended in offshore design codes [3,4] may result in significant errors in estimating the structure's natural frequency.

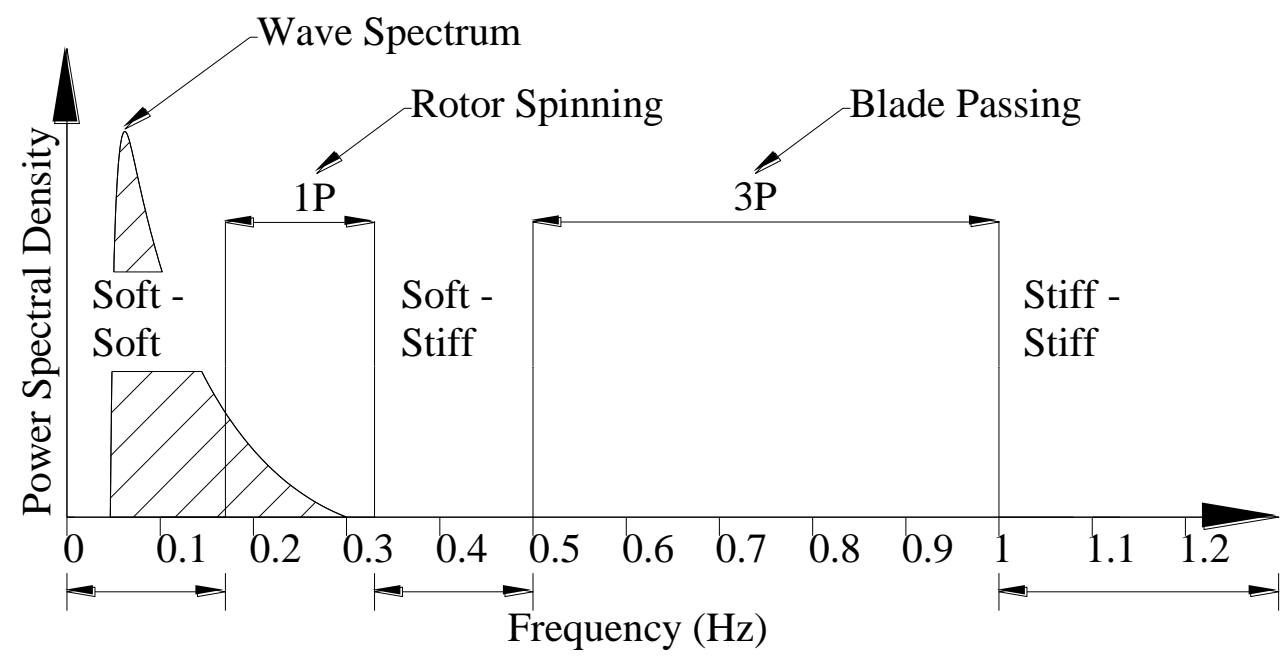

Fig. 1. Frequency bands for typical offshore wind turbines.

Understanding a soil's dynamic stiffness is also very important with regard to Structural Health Monitoring (SHM). Recent advances in SHM use changes in the modal properties of structures in order to infer some form of damage [1]. In the case of bridges, most of the work to date has focused on monitoring the superstructure. More recent research has begun to focus on using these damage 
detection methodologies on sub-structural elements (see [5-7]). In these cases, the analyses can be quite sensitive to the soil stiffness assumed in the design where the dynamic oscillations typically remain in the small-strain region.

DSSI is also very important in the field of earthquake engineering where propagating ground motion waves can generate high stresses in a pile foundation. The stiffness contrast between a pile and the surrounding soil tends to modify the transmitted excitation from seismic shear waves leading to an effect known as kinematic interaction. Coupled with this phenomenon, the dynamic response of a superstructure to a seismic excitation leads to additional deformations in the pile foundation, an effect known as inertial interaction [8]. It is very important to be able to accurately model the various components of a soil-pile dynamic system so that the detrimental effects of external actions may be mitigated by design. There are a variety of methods available to model the dynamic behaviour of soilpile systems.

\subsection{Winkler modelling approach}

In this paper an approach, termed the Winkler model, commonly employed by structural engineers for both static and dynamic soil-structure interaction problems is considered. The model considers the soil as a system of discrete, mutually independent, closely-spaced, springs $[9,10]$. The pressuredeflection relationship at any point of the foundation element can be generally represented by the equation shown in Eq. (1), (in the absence of energy loss or inertial contributions).

$$
p(x, t)=\mathrm{k} w(x, t)
$$

where $\mathrm{p}(\mathrm{x}, \mathrm{t})$ is the applied pressure $\left(\mathrm{N} \mathrm{m}^{-2}\right)$ at a given unit of time, $\mathrm{w}(\mathrm{x}, \mathrm{t})$ is the deflection $(\mathrm{m})$ at a given time, and $\mathrm{k}$ is the coefficient of subgrade reaction $\left(\mathrm{N} \mathrm{m}^{-3}\right)$. The key uncertainty with using a Winkler model for dynamic applications lies with the specification of the parameters required to model the behaviour of the soil under dynamic motion. The issues arise due to the nonlinear and inelastic nature of soil when deformations are large. These parameters include, among others; the initial (elastic) stiffness, load-displacement response curves, cyclic degradation and hardening parameters, unload-reload stiffness parameters and radiation and hysteretic damping coefficients [11]. A number of authors have developed dynamic beam on nonlinear Winkler foundation (BNWF) models for the purposes of modelling the soil-structure response under large-strain dynamic loading. This topic has received much interest in recent times from researchers working in the area of earthquake engineering $[8,12,13]$. Both Nogami et al. [14] and Allotey et al. [11] give a good overview of the development of general nonlinear soil-pile interaction models for dynamic applications. In [11], a comprehensive discussion is given on the various soil-structure interaction response features and how they can be modelled in a BNWF model. In particular, the paper highlights the inefficiencies of static nonlinear models in accounting for cycle-by-cycle soil-structure interaction 
effects and kinematic interaction effects for seismic applications, hence the need for the improved dynamic model. A generic cyclic normal force-displacement scheme (cyclic p-y) incorporating backbone curves, unload-reload curves, cyclic degradation and radiation damping as well as other modelling aspects is discussed. Backbone curves are analogous to monotonic loading curves (static p$y$, see [4]) and represent the nonlinear load-displacement response of the system due to the first application of the load (virgin loading). These can be represented by either a nonlinear or a multilinear curve. Unload-reload curves represent the soil-structure behaviour when the load is removed and reapplied (as per a cyclic load regime). The purpose of modelling this aspect is such that the previous maximum force (stress) applied to the soil is memorized by the model. Some coupled BNWF models are capable of directly modelling cyclic degradation, however most other models require the specification of parameters that are a function of dissipated hysteretic energy or cumulative displacement ductility. Generally, cyclic degradation can be modelled by specifying stiffness or strength degradation factors to be applied to unload-reload curves. The rate of degradation for variable amplitude loading will depend on the number of load cycles. Radiation damping, caused by the propagation of waves away from the foundation, can be modelled using a linear or nonlinear dashpot attached in parallel with a Winkler spring. There are a range of methods available to specify damping constants for use with this model.

Kampitsis et al. [8] describe the development of an advanced dynamic BNWF model, developed based on Timoshenko beam theory, to investigate its accuracy in terms of modelling kinematic and inertial interaction of a soil-pile-structure system for seismic applications. The model encompasses the effects of geometrical nonlinearity, rotary inertia and shear deformation. A case study of a pilecolumn-bridge deck founded in two cohesive soil layers and subjected to earthquake excitation is investigated. The efficacy of the proposed model is investigated against a simplified beam finiteelement (FE) model and a fully 3-D continuum FE scheme. The spring configuration in the model consists of a nonlinear p-y spring connected in series with an elastic spring-damper element. The near field plastification of the soil is accounted for by the nonlinear spring and the far-field confining stiffness (viscoelastic characteristics) is incorporated by the elastic spring-damper, known as a KelvinVoigt element (see [15]). The model is shown to be capable of producing accurate results with a fraction of the computational time required by the full 3-D FE model. Boulanger et al. [13] evaluates the performance of a dynamic BNWF model against the results of a series of dynamic centrifuge model tests, where two pile supported structures are founded in a soil profile comprising soft clay overlying sand and subjected to nine earthquake shaking events. A parametric study is undertaken to assess the sensitivity of the analysis results to the chosen dynamic p-y parameters and site response calculations. The backbone curves for the p-y analysis in the clay were based on Matlock's recommendation [16] for soft clay and the backbone curves for the sand layer were based on recommendations from the American Petroleum Institute (API) [4]. However, the initial stiffness 
component for the sand p-y curve was estimated using the elastic theory of Vesic [17], with the smallstrain shear modulus $\left(\mathrm{G}_{0}\right)$ adopted in the site response analyses. The dynamic response of the freefield soil and the dynamic p-y analyses were undertaken separately. The results of the sensitivity studies suggest that there is a greater uncertainty associated with the site response calculations than with the dynamic p-y analysis when predicting the superstructure response for the conditions tested in this study. However, by varying the dynamic p-y parameters by different amounts, the peak superstructure displacement varied in the range of $-26 \%$ to $+24 \%$ but the change was only greater than $\pm 10 \%$ for 6 of the 32 parametric cases. The method, therefore, would still seem to be quite sensitive to the magnitude of the parameters chosen to model the nonlinear dynamic response.

\subsection{Synopsis of paper}

As mentioned above, one of the primary issues facing researchers and designers is that beam on nonlinear Winkler foundation models for dynamic applications typically require the specification of many parameters and the results obtained in many cases can be quite sensitive to the parameters chosen. Undertaking additional site investigations or laboratory testing is often required to accurately calibrate the models developed so as to ensure that the results obtained are realistic. In this paper, the specification of an initial stiffness parameter and its effect on the resulting dynamic response at very low strain levels is investigated. For small-strain applications, a unique value of stiffness, either the small-strain shear $\left(\mathrm{G}_{0}\right)$ or Young's $\left(\mathrm{E}_{0}\right)$ moduli can be used to model the elastic soil response. This parameter is also one of the key inputs required to model the initial stiffness response when largestrain nonlinear dynamic response is modelled (see [13]). The primary issue considered in this paper is the specification of an initial stiffness parameter that accurately reflects the in-situ small-strain stiffness of the combined soil-pile system. This initial stiffness parameter, known as the coefficient of subgrade reaction in a static analogue, can be a difficult parameter to specify in that it typically varies with loading scheme, geometry of the foundation and the type of subgrade material.

This paper presents a comparison of the performance of five different subgrade reaction models used in the small-strain dynamic modelling of a soil-pile system. These models are discussed in section 2.0. A numerical model programmed in MATLAB considers the pile and surrounding soil as a beam supported by linear-elastic springs, as per the Winkler approximation for small-strain applications. In the first instance, a range of synthetic soil stiffness profiles and pile geometries are generated and a sensitivity analysis is performed to predict the natural frequencies and mode shapes of the system and assess their sensitivity to changes in the pile geometry and soil properties. Secondly, a field study is performed in which two $340 \mathrm{~mm}$ diameter steel pipe piles were driven to various slenderness ratios (depth, L divided by diameter, D) and their natural frequency and damping ratios are measured. The natural frequency is measured by inputting a lateral excitation to the pile head using a calibrated modal hammer and measuring the resulting acceleration from accelerometers placed along the pile 
shaft. These input force and output acceleration signals are used to develop Frequency Response Functions (FRFs) in order to estimate their frequency content. Damping is measured using a curvefitting technique to estimate the damping ratio of the pile-soil system from the acceleration timedomain decay resulting from the application of the impulse force. An estimate of the small-strain shear modulus $\left(\mathrm{G}_{0}\right)$ for the site was obtained using shear wave velocity data from a site investigation. This small-strain $G_{0}$ value was used to estimate coefficients of subgrade reaction for the pile-soil systems using a range of theories discussed in section 2.0. A direct modelling of the experimental impact test for each pile was undertaken and the ability of each subgrade reaction model to predict the pile response at low strain levels is assessed and discussed in the final section of the paper.

\subsection{Background to subgrade reaction theories}

There have been a number of methods proposed to model soil-structure interaction using Winkler springs. These models were typically developed for the application to static problems; however, their efficacy at modelling the small-strain (elastic) dynamic behaviour is of interest in this paper. Some models account for the flexural rigidity of the foundation to which the spring is attached whereas other methods specify spring constants without consideration of foundation geometry or flexibility. A brief review of key assumptions in these models is discussed.

Biot [18] presented a solution for the problem of an infinite beam with a concentrated load, resting on a 3-D elastic soil continuum. He found a correlation between the continuum elastic theory and the Winkler model by equating the maximum moments in the infinite beam and developed an empirical equation for the coefficient of subgrade reaction, $k_{s}[19]$ as shown in Eq. (2).

$$
k_{s}=\frac{0.95 E_{0}}{D\left(1-v_{s}^{2}\right)}\left[\frac{D^{4} E_{0}}{\left(1-v_{s}^{2}\right) E I}\right]^{0.108}
$$

where $\mathrm{E}_{0}$ is the small-strain Young's modulus of the soil elements $\left(\mathrm{N} \mathrm{m}^{-2}\right), \mathrm{D}$ is the width of the foundation element $(\mathrm{m})$, EI is the flexural rigidity of the foundation element $\left(\mathrm{N} \mathrm{m}^{2}\right)$, and $v_{s}$ is the Poisson's ratio of the foundation soil. Using a similar approach, Vesic [17] derived an equation for $k_{s}$ by matching the maximum displacements of the infinite beam [19] as shown in Eq. (3).

$$
k_{s}=\frac{0.65 E_{0}}{D\left(1-v_{s}^{2}\right)}\left[\frac{E_{0} D^{4}}{E I}\right]^{1 / 12}
$$

which is of similar form to Eq. (2). A modified version of the equation shown in Eq. (3) was used by Ashford and Juirnarongrit [20] for modelling the dynamic response of piles at low strains to investigate the effect of pile diameter on the initial modulus of subgrade reaction. They substituted the constant value 0.65 in Eq. (3) for 1.0 since this was deemed to provide the closest agreement between 
Vesic's lower-bound estimation and an upper-bound version provided by Bowles [21] which indicated that the modulus of subgrade reaction should be doubled to account for soil presence on both sides of the pile. The value of 1.0 was found to provide the closest agreement between both estimations, since in reality for a pile under lateral loading gapping may occur, and hence loss of soil contact may occur. Since piles are commonly modelled as beams supported by springs for both static and dynamic applications, both the aforementioned formulations for coefficient of subgrade reaction are suitable for comparison in this paper.

Comparable expressions have been developed to compute the coefficient of horizontal subgrade reaction for buried circular conduits (e.g. pipeline) [22,23]. Since these are similar to piles, the approaches are considered in this study. Meyerhof \& Baike $[22,23]$ proposed an equation in which the coefficient of subgrade reaction for a circular cross-section is expressed as a function of the soil elastic modulus $\left(\mathrm{E}_{0}\right)$, the Poisson's ratio and the element width (D). The soil is assumed to be isotropic, homogeneous and to have a linear stress-strain relationship, (a viable assumption for smallstrain dynamic loading). This is shown in Eq. (4).

$$
k_{s}=\frac{E_{0}}{D\left(1-v_{s}^{2}\right)}
$$

Alternative formulations were developed by Klopple \& Glock [22-24], See Eq. (5) and Selvadurai [23,24], Eq. (6).

$$
\begin{gathered}
k_{s}=\frac{2 E_{0}}{D\left(1+v_{s}\right)} \\
k_{s}=\frac{0.65}{D} \frac{E_{0}}{\left(1-v_{s}^{2}\right)}
\end{gathered}
$$

The variations evident in Equations 2 to 6 arise from the adoption of different assumptions in their formulation. As a result, for identical soil conditions and pile geometries, different estimates of soil stiffness are obtained. In order to highlight the variation of $k_{s}$ values obtained using the five methods considered, a sensitivity study was performed in the first instance in which the coefficient of subgrade reaction was calculated for a range of pile diameters and constant soil densities. For the purpose of this preliminary study, Young's moduli $\left(\mathrm{E}_{0}\right)$ values of $50 \mathrm{MPa}, 100 \mathrm{MPa}$ and $150 \mathrm{MPa}$ are used to approximate the stiffness of loose, medium dense and dense sand deposits at small strains.

The difficulty faced by a designer in choosing stiffness parameters is evident in Table 1 , which presents values of $k_{s}$ predicted using the five models for a $0.75 \mathrm{~m}$ diameter pile installed in soil with a constant elastic modulus $\left(\mathrm{E}_{0}\right)$ of $50 \mathrm{MPa}$. The predicted $k_{s}$ values ranged from $30.2 \mathrm{MN} \mathrm{m}^{-3}$ to 121.2 
$\mathrm{MN} \mathrm{m}^{-3}$. The two methods most widely used for foundation analysis, Biot's and Vesic's produced $k_{s}$ values which varied by $\approx 27 \%$. The effect of increasing the pile diameter from $0.25 \mathrm{~m}$ to $2 \mathrm{~m}$ for the three soil densities considered is illustrated in Fig. 2, which reveals:

1. As expected the $k_{s}$ value increased as the soil density increased. For a given sand density, $k_{s}$ reduced as the pile diameter increased.

2. The Klopple and Glock model (Eq. 5) predicted the highest values of $k_{s}$, whilst the Vesic model (Eq. 3) gave the lowest.

3. Whilst significant differences were evident between the $k_{s}$ values predicted using the different models, the relative difference depended on the sand density and pile geometry. For a pile with $\mathrm{D}=0.5 \mathrm{~m}$ in loose sand the Vesic model predicted $k_{s}$ values approximately $24 \%$ of those predicted using the Klopple and Glock model. For the same pile geometry in dense sand, predicted $k_{s}$ values using the Vesic model were approximately $26.6 \%$ of those using the Klopple and Glock model.

Table 1 Comparison of coefficients of subgrade reaction models

\begin{tabular}{|l|l|l|l|l|l|l|l|l|l|}
\hline \multicolumn{3}{|c|}{ Pile Properties } & \multicolumn{3}{c|}{ Soil Properties } & \multicolumn{4}{c|}{ Coef. Subgrade Reaction $k_{s}\left(\mathrm{MN} \mathrm{m}^{-3}\right)$} \\
\hline $\mathrm{D}(\mathrm{m})$ & $\mathrm{E}(\mathrm{GPa})$ & $\mathrm{I}\left(\mathrm{m}^{4}\right)$ & $v_{s}$ & $\mathrm{E}_{\mathrm{s}}(\mathrm{MPa})$ & Biot & Vesic & $\begin{array}{l}\mathrm{M} \& \\
\mathrm{~B}\end{array}$ & $\mathrm{~K} \& \mathrm{G}$ & Selvadurai \\
\hline 0.75 & 200 & 0.00677 & 0.1 & 50 & 39.6 & 30.2 & 67.3 & 121.2 & 43.8 \\
\hline
\end{tabular}


(a)
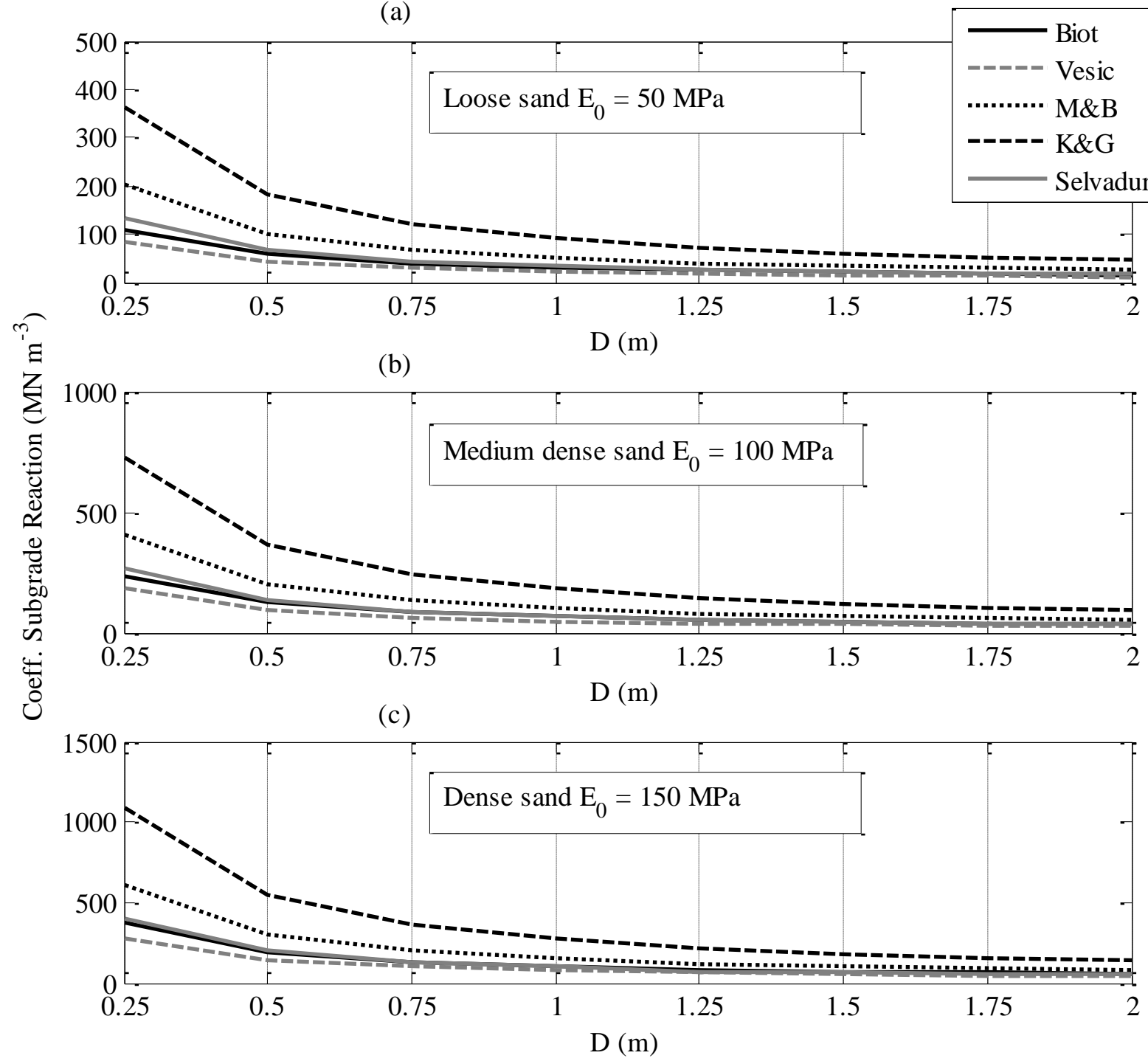

Fig. 2. Variation of coefficient of subgrade reaction with diameter and soil elastic modulus. (a) Loose sand with $\mathrm{E}_{0}=50 \mathrm{MPa}$; (b) Medium dense sand with $\mathrm{E}_{0}=100 \mathrm{MPa}$; (c) Dense sand with $\mathrm{E}_{0}=150$ MPa.

\subsection{Structural modelling}

In order to perform the sensitivity analyses of the different frequency responses predicted by each formulation a numerical finite-element model of the pile and soil was created in the MATLAB programming environment. Pile-soil systems can be modelled using beam and spring elements, whereby the beam elements model the pile structural behaviour and the spring elements model the soil behaviour. P-y springs can be used to model lateral soil behaviour whereas $\tau$-z springs can be used to model the vertical soil reaction along the pile. As the current analysis solely pertains to lateral pile response, only the elements relevant to lateral motion are modelled. The pile is therefore modelled using standard four degree of freedom (4-DOF) Euler-Bernoulli beam elements, each containing two nodes. Each node has a translational and rotational degree of freedom and cannot deform axially. The 
mass and stiffness matrices of this type of element are available in [25]. The influence of the soil on the dynamic system was modelled using a linear p-y spring, attached to one node of each beam element (see Fig. 3). This combined element has five degrees of freedom (5-DOF), with the lateral translation governed by a combination of the beam element flexural rigidity and the soil-spring lateral stiffness (see the insert in Fig. 3) [10]. It is noteworthy that the exclusion of vertical degrees of freedom (and $\tau$-z springs) from the model will have no effect on the modelled lateral response, due to the 1D nature of the system. A system of elemental stiffness and mass matrices were assembled together in line with the procedure outlined in [25] in order to create global stiffness and mass matrices capable of representing the entire pile-soil system. The dynamic response of this discretized finite-element model can be obtained by solving the second-order matrix differential equation shown in Eq. (7).

$$
[\mathbf{M}]\left\{\ddot{\mathbf{x}}_{\mathbf{p}}\right\}+[\mathbf{C}]\left\{\dot{\mathbf{x}}_{\mathbf{p}}\right\}+[\mathbf{K}]\left\{\mathbf{x}_{\mathbf{p}}\right\}=\{\mathbf{F}\}
$$

where $[\mathbf{M}],[\mathbf{C}]$ and $[\mathbf{K}]$ are the global mass, damping and stiffness matrices for the combined system. The vectors $\mathbf{x}_{\mathbf{p}}, \dot{\mathbf{x}}_{\mathbf{p}}$ and $\ddot{\mathbf{x}}_{\mathbf{p}}$ describe the displacement, velocity and acceleration of each degree of freedom in the model at a given time step in the analysis. $\mathbf{F}$ is a vector describing the external forces acting on each degree of freedom for a given time step in the analysis.

A time-domain dynamic analysis can be undertaken by solving the second-order differential equation shown in Eq. (7) using numerical integration. There are a number of integration methods available that can be broadly segregated into implicit and explicit methods. Implicit integration methods such as Wilson-theta and Newmark methods (see [26]) can provide an unconditionally stable solution, through careful choice of the integration parameters. The integration scheme employed for modelling in this paper is the Wilson-Theta method as described in [27]. A value of $\boldsymbol{\theta}=1.4$ was chosen as this is known to provide unconditional stability in the model [26]. It is noteworthy that the Wilson-theta method may underestimate the contribution from higher order modes of vibration in the transient response, therefore if a more comprehensive analysis is desired (i.e. observing higher modes), the Newmark method may be more appropriate. However, for the purpose of obtaining the first natural frequency response in this paper, either method works well. Integrating Eq. (7) allows for obtaining numerical displacements, velocities and accelerations in the time-domain from any degree of freedom in the model.

Damping is modelled as Rayleigh damping, where the damping matrix [C] is formulated as a linear combination of the mass and stiffness matrices for the combined soil-pile system. This is shown in Eq. (8).

$$
[\mathbf{C}]=\alpha[\mathbf{M}]+\beta[\mathbf{K}]
$$


where $\alpha=2 \xi \omega_{1} \omega_{2} /\left(\omega_{1}+\omega_{2}\right)$ and $\beta=2 \xi /\left(\omega_{1}+\omega_{2}\right) . \omega_{1}$ and $\omega_{2}$ are the first and second circular frequencies of the system and $\xi$ is the damping ratio of the system. Damping can be modelled by specifying a damping ratio and the first and second circular frequencies can be obtained by performing an eigenvalue analysis in the model. This is achieved by specifying a system matrix as shown in Eq. (9).

$$
[\mathbf{D}]=[\mathbf{M}]^{-1}[\mathbf{K}]
$$

where [D] is the system matrix, obtained from the matrix division of the global stiffness and mass matrices. The eigenvalues and eigenvectors of this matrix represent the system un-damped natural frequencies and mode shapes and are obtained using MATLAB's in-built 'eig' function. The degrees of freedom corresponding to laterally displaced mode shapes are extracted from each model such that a comparison of mode shapes can be undertaken for each formulation of subgrade reaction. A schematic of the numerical model is shown in Fig. 3 with an insert showing the degrees of freedom for the combined pile-soil elements.

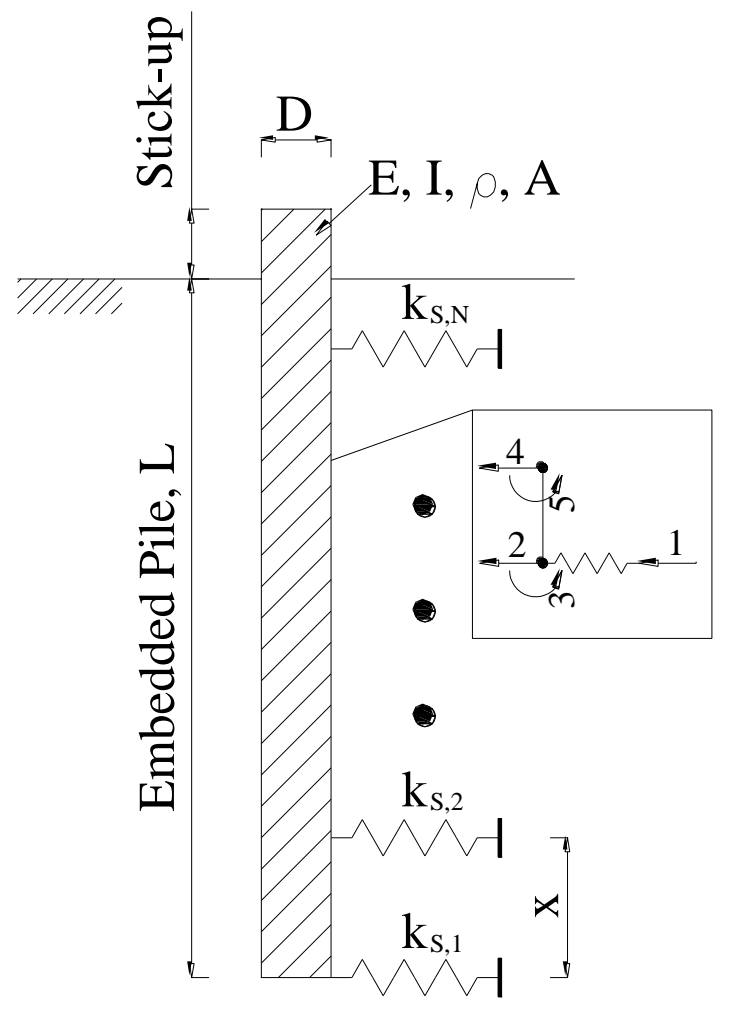

Fig. 3. Embedded pile numerical schematic. 


\subsection{Sensitivity study}

\subsection{Background to analysis \& soil stiffness}

In order to conduct a sensitivity study investigating the different frequency responses predicted by the implementation of different subgrade reaction (initial) stiffnesses, it was first necessary to develop synthetic soil profiles for comparison purposes. The profiles considered in this analysis represent a loose sand deposit and a dense sand deposit and they vary with effective stress (depth). Open-ended, tubular steel piles embedded $\mathrm{L}=10,20,30$ and $40 \mathrm{~m}$ into the sand profiles are considered as the foundation pile element, each with a $1 \mathrm{~m}$ stick-up above ground level (see Fig. 3). The pile diameter (D) was varied between $0.25 \mathrm{~m}$ and $10 \mathrm{~m}$ using the increments shown in Table 2 , such that L/D ratios ranging from 4 to 40 were represented. The pile thickness is maintained constant at $50 \mathrm{~mm}$ for each case. The sensitivity design cases considered are summarized in Table 2 . The grey cells represent design cases considered.

Table 2. Range of pile geometries considered in the sensitivity study.

\begin{tabular}{|c|c|c|c|c|c|r|r|}
\hline \multicolumn{2}{|c|}{$\begin{array}{c}\text { Loose / } \\
\text { Dense } \\
\text { Sand Cases }\end{array}$} & \multicolumn{7}{|c|}{ D (m) } \\
\cline { 2 - 8 } & 0.25 & 0.5 & 1 & 2 & 5 & 10 \\
\hline \multirow{4}{*}{ L (m) } & 10 & & & & & & \\
\cline { 2 - 8 } & 20 & & & & & & \\
\cline { 2 - 8 } & 30 & & & & & & \\
\cline { 2 - 8 } & 40 & & & & & & \\
\hline
\end{tabular}

Soil profiles with depth-dependent stiffness were created. In order to achieve this, a Young's modulus value that varied with depth was hypothesized based on a number of assumptions. In the first instance, the American Petroleum Institute design code [4], which describes sand behaviour based on relative density $\left(D_{r}\right)$ values, was used to classify soil stiffness. Relative density values of $30 \%$ and $80 \%$ were considered to approximate the conditions required to classify sand profiles as "loose" and "dense" [28]. These $D_{r}$ values were considered constant over the numerical depth of embedment of the pile. Synthetic Cone Penetration Test (CPT) profiles were generated based on these relative density values using a relation developed by [29] and shown in Eq. (10).

$$
D_{r}=\frac{1}{2.91} \ln \left\{\frac{q_{c}}{\left[60\left(\sigma_{v}^{\prime}\right)^{0.7}\right]}\right\}
$$

which can be re-arranged in order to obtain a synthetic cone tip resistance parameter $\left(\mathrm{q}_{\mathrm{c}}\right)$ profile as follows: 


$$
q_{c}=60\left(\sigma_{v}^{\prime}\right)^{0.7} \exp \left(2.91 D_{r}\right)
$$

where $\mathrm{q}_{\mathrm{c}}$ is the cone tip resistance $(\mathrm{kPa})$ and $\sigma{ }_{\mathrm{v}}$ is the vertical effective stress $(\mathrm{kPa})$.

For the loose and dense sand cases, values of bulk density $(\gamma)$ were taken as $18 \mathrm{kN} \mathrm{m}^{-3}$ and $20 \mathrm{kN} \mathrm{m}^{-3}$ respectively and the analysis assumes saturated conditions, with $\gamma_{\mathrm{w}}=10 \mathrm{kN} \mathrm{m}^{-3}$. These $\mathrm{q}_{\mathrm{c}}$ profiles were converted to equivalent profiles of shear modulus $\left(\mathrm{G}_{0}\right)$ using the expression shown in Eq. (11) $[30,31]$.

$$
\mathrm{G}_{0}=q_{c}\left[A+B \eta-C \eta^{2}\right]^{-1}
$$

where $\mathrm{A}=0.0203 ; \mathrm{B}=0.00125 ; \mathrm{C}=1.216 \mathrm{E}-6$ and $\eta=q_{c}\left(P_{a} \sigma^{\prime}{ }^{\prime}\right)^{-0.5} . \mathrm{P}_{\mathrm{a}}=100 \mathrm{kPa}, \sigma_{v 0}^{\prime}=$ vertical effective stress $(\mathrm{kPa})$. The resulting $\mathrm{G}_{0} / \mathrm{q}_{\mathrm{c}}$ values for the soil profiles assumed ranged from 13-24 for the loose sand to 4-9 for the dense sand profiles. The Young's modulus $\left(\mathrm{E}_{0}\right)$ profiles were obtained from the $\mathrm{G}_{0}$ profiles using Eq. (12), with a small-strain Poisson ratio of $v=0.1$. The synthetic $\mathrm{q}_{\mathrm{c}}$ and $\mathrm{E}_{0}$ profiles that were derived are shown in Fig. 4.

$$
E_{0}=2 G_{0}(1+v)
$$

These $E_{0}$ profiles were used with each of the subgrade reaction formulations described in section 2.0 to generate modulus of subgrade reaction profiles for use in the dynamic analysis of each pile design case shown in Table 2. The first step involved converting the coefficient of subgrade reaction $\left(k_{s}\right)$ values to a profile of the modulus of subgrade reaction $(\mathrm{K})$, by multiplying by the pile diameter (D). The next step involved creating individual spring stiffness moduli by multiplying the modulus of subgrade reaction $(\mathrm{K})$ at a given depth by the spacing between subsequent springs at that depth (see Fig. 3). Spring spacing was maintained constant at $0.25 \mathrm{~m}$ for each design case considered. 
(a)

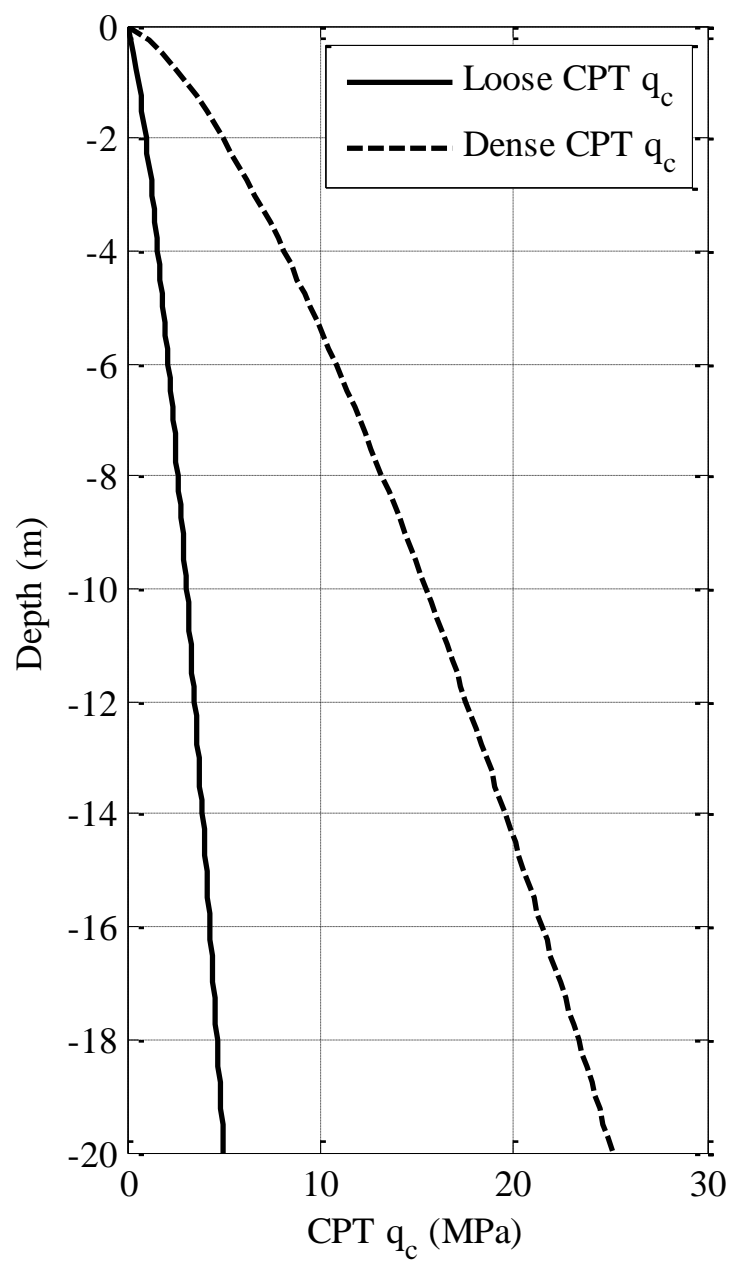

(b)

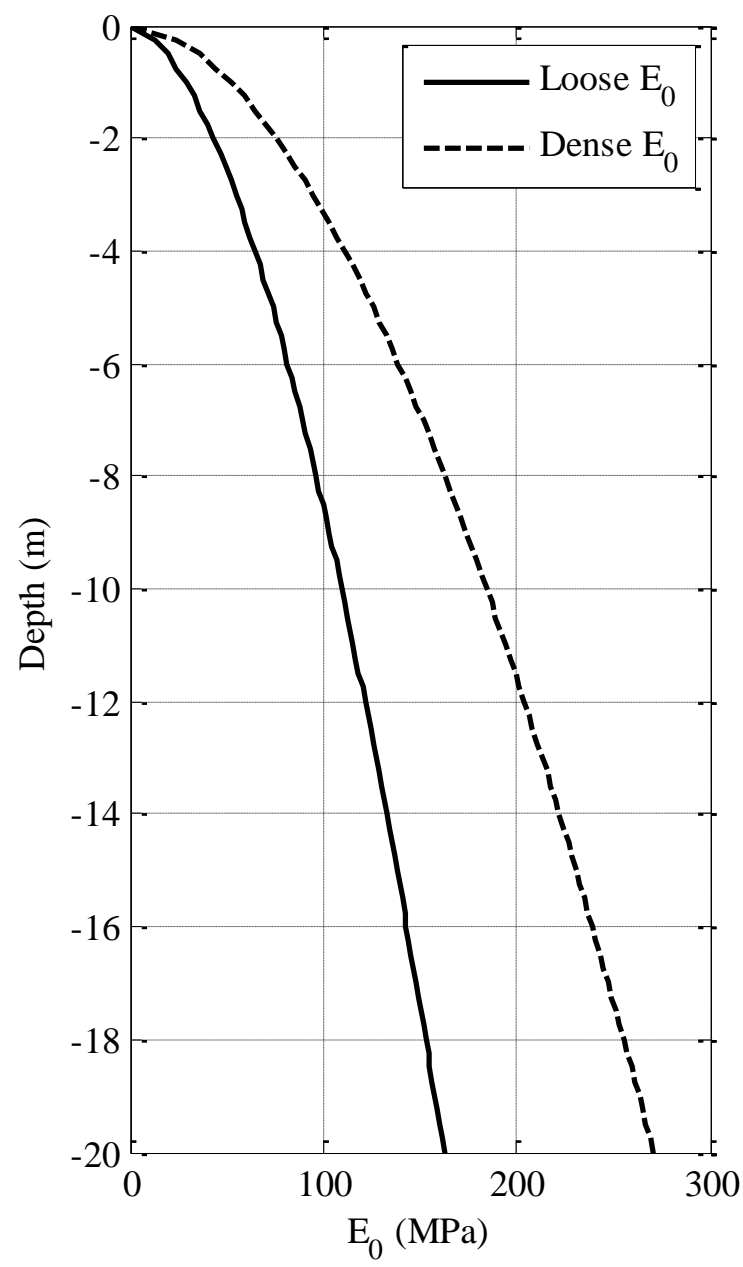

Fig. 4. Synthetic soil profiles. (a) Loose and dense CPT q profiles; (b) Loose and dense Young's modulus $\left(\mathrm{E}_{0}\right)$ profiles.

\subsection{Dynamic response}

The un-damped natural frequencies predicted by the numerical models for each subgrade reaction formulation are summarized in Table 3. Both the loose sand case and the dense sand case are presented, and the coefficient of variation for each $\mathrm{L}$ and $\mathrm{D}$ is calculated. The coefficient of variation is defined as the sample standard deviation $(\sigma)$ divided by the sample mean $(\mu)$. The un-damped natural frequencies were obtained by performing an eigenvalue analysis in each numerical model. The percentage difference between Vesic's model and Biot's model, which are most widely used for foundation design, was also calculated (see Table 3). Biot's model is seen to provide a higher estimate of the natural frequency with the difference becoming larger as the L/D ratio of the pile decreased. For $\mathrm{L} / \mathrm{D}$ ratios typical of offshore piles ( $\mathrm{L} / \mathrm{D} \approx 5$ ), the difference between the natural frequency predicted using these two subgrade models were in the range 13.95 to $16.7 \%$ for loose sand and $14.9 \%$ to $16.9 \%$ for dense sand. A comparison of frequencies predicted using all the models is 
presented graphically in Fig. 5 for the loose sand case, with Fig. 5a illustrating the effect of varying the pile diameter for a pile of fixed length, $\mathrm{L}=10 \mathrm{~m}$. Fig. $5 \mathrm{~b}$ considers the effect of varying the pile length for a pile with a fixed diameter, $\mathrm{D}=1 \mathrm{~m}$. The data reveal that:

(i) When the pile length was fixed at $10 \mathrm{~m}$ (Fig. 5a) all models predicted that the frequency decreased when the pile diameter increased above $0.5 \mathrm{~m}$.

(ii) When the pile diameter was fixed at $1 \mathrm{~m}$ (Fig. 5b) the natural frequency of the piles was not very sensitive to the pile length in the range considered, and was relatively constant for $\mathrm{L}>20 \mathrm{~m}$ or $\mathrm{L} / \mathrm{D}>20$.

(iii) It is noteworthy that the formulations put forward by Biot and Vesic for the spring stiffness are dependent on the pile structural properties as well as the soil input stiffness, whereas the remaining methods are independent of the pile properties. This can lead to changes in the order of predicted responses depending on the magnitude of the pile structural properties under investigation.
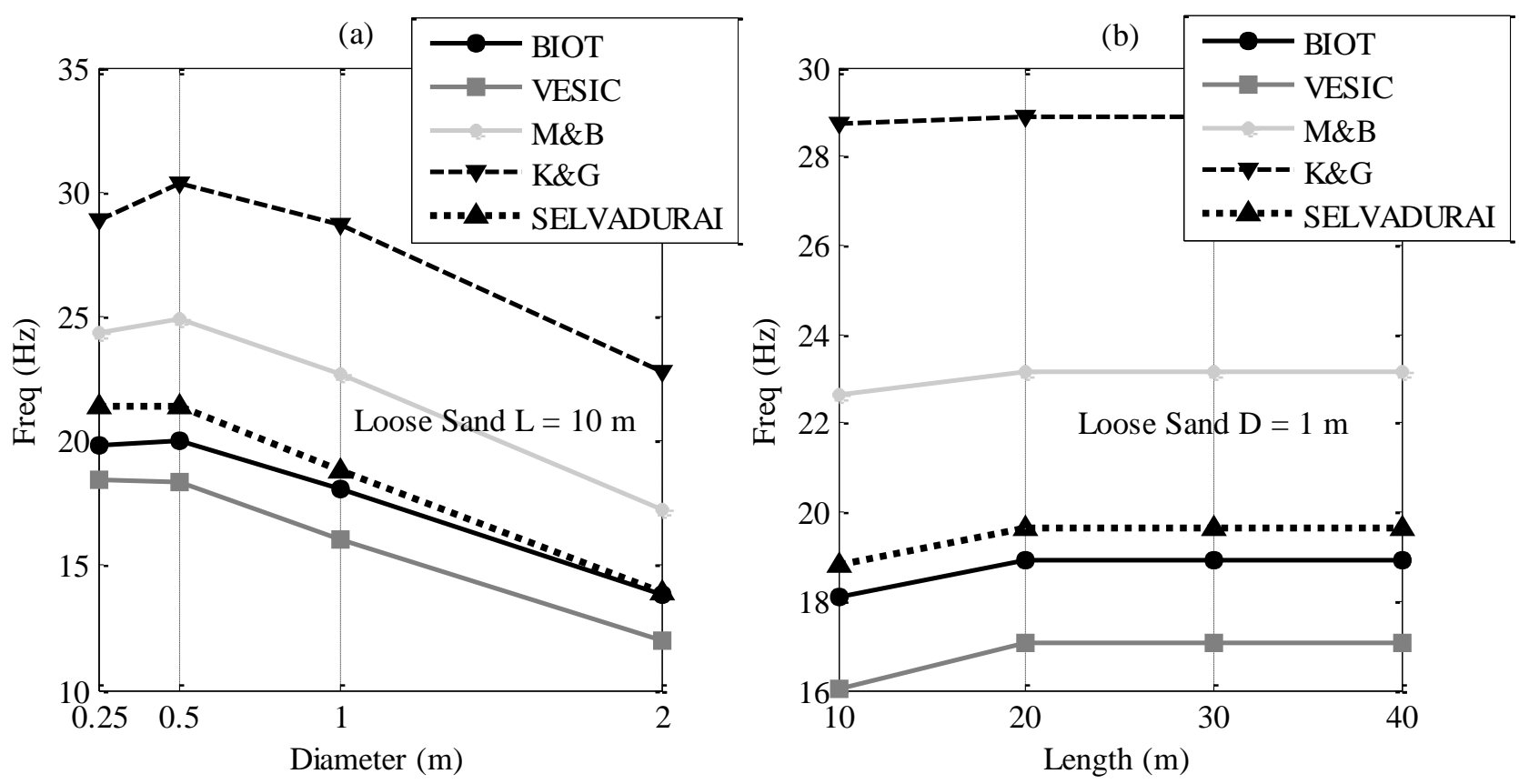

Fig. 5. Comparison of predicted frequency responses for each subgrade reaction theory for loose sand.

(a) Frequency response by each theory for $\mathrm{L}=10 \mathrm{~m}$ and varied pile diameter; (b) Frequency response by each theory for $\mathrm{D}=1 \mathrm{~m}$ and varied penetration depth. 
Published in Soil Dynamics and Earthquake Engineering, 2016 (81C) pp. 27-41

Table 3a Comparison of design cases for loose sand profile

\begin{tabular}{|c|c|c|c|c|c|c|c|c|c|c|}
\hline \multicolumn{11}{|c|}{ LOOSE SAND: } \\
\hline $\begin{array}{c}\mathrm{L} \\
{[\mathrm{m}]}\end{array}$ & $\begin{array}{c}\mathrm{D} \\
{[\mathrm{m}]}\end{array}$ & $\begin{array}{l}B I O T \\
{[\mathrm{~Hz}]}\end{array}$ & $\begin{array}{c}\text { VESIC } \\
{[\mathrm{Hz}]}\end{array}$ & $\begin{array}{c}M \& B \\
{[\mathrm{~Hz}]}\end{array}$ & $\begin{array}{l}K \& G \\
{[\mathrm{~Hz}]}\end{array}$ & $\begin{array}{l}S E L V \\
{[H z]}\end{array}$ & Mean: & $\begin{array}{l}\text { Standard } \\
\text { Dev: }\end{array}$ & Coef. Var: & $\begin{array}{c}\text { \% Diff } \\
\text { Biot } \\
\& \\
\text { Vesic: }\end{array}$ \\
\hline 10 & 0.25 & 19.80 & 18.41 & 24.39 & 28.86 & 21.43 & 22.576 & 4.158 & 0.184 & 7.288 \\
\hline 10 & 0.5 & 20.02 & 18.31 & 24.86 & 30.38 & 21.38 & 22.990 & 4.783 & 0.208 & 8.952 \\
\hline 10 & 1 & 18.08 & 16.01 & 22.64 & 28.71 & 18.81 & 20.850 & 5.007 & 0.240 & 12.184 \\
\hline 10 & 2 & 13.80 & 12.00 & 17.20 & 22.80 & 13.90 & 15.940 & 4.269 & 0.268 & 13.953 \\
\hline 20 & 0.5 & 20.03 & 18.32 & 24.87 & 30.39 & 21.38 & 22.997 & 4.781 & 0.208 & 8.944 \\
\hline 20 & 1 & 18.92 & 17.04 & 23.15 & 28.89 & 19.62 & 21.524 & 4.673 & 0.217 & 10.450 \\
\hline 20 & 2 & 17.02 & 15.01 & 20.33 & 25.77 & 16.98 & 19.021 & 4.230 & 0.222 & 12.530 \\
\hline 20 & 5 & 12.40 & 10.60 & 14.40 & 19.10 & 11.70 & 13.640 & 3.352 & 0.246 & 15.652 \\
\hline 30 & 1 & 18.92 & 17.05 & 23.15 & 28.89 & 19.63 & 21.527 & 4.672 & 0.217 & 10.442 \\
\hline 30 & 2 & 17.14 & 15.23 & 20.38 & 25.78 & 17.13 & 19.134 & 4.153 & 0.217 & 11.814 \\
\hline 30 & 5 & 13.98 & 12.02 & 16.00 & 20.78 & 13.11 & 15.179 & 3.453 & 0.227 & 15.082 \\
\hline 40 & 1 & 18.92 & 17.05 & 23.15 & 28.89 & 19.63 & 21.527 & 4.672 & 0.217 & 10.442 \\
\hline 40 & 2 & 17.15 & 15.23 & 20.39 & 25.78 & 17.13 & 19.137 & 4.152 & 0.217 & 11.813 \\
\hline 40 & 5 & 14.45 & 12.58 & 16.38 & 20.95 & 13.63 & 15.597 & 3.304 & 0.212 & 13.862 \\
\hline 40 & 10 & 11.66 & 9.86 & 12.81 & 16.90 & 10.40 & 12.324 & 2.802 & 0.227 & 16.731 \\
\hline & & & & & & & & $\operatorname{Max}$ & 0.2678436 & 16.731 \\
\hline & & & & & & & & Min & 0.1841719 & 7.288 \\
\hline
\end{tabular}

Table 3b Comparison of design cases for dense sand profile

\begin{tabular}{|c|c|c|c|c|c|c|c|c|c|c|}
\hline \multicolumn{11}{|c|}{ DENSE SAND: } \\
\hline $\begin{array}{c}\mathrm{L} \\
{[\mathrm{m}]}\end{array}$ & $\begin{array}{c}\mathrm{D} \\
{[\mathrm{m}]}\end{array}$ & $\begin{array}{l}B I O T \\
{[\mathrm{~Hz}]}\end{array}$ & $\begin{array}{c}\text { VESIC } \\
{[\mathrm{Hz}]} \\
\end{array}$ & $\begin{array}{l}M \& B \\
{[H z]}\end{array}$ & $\begin{array}{l}K \& G \\
{[H z]}\end{array}$ & $\begin{array}{c}\text { SELV } \\
{[\mathrm{Hz}]} \\
\end{array}$ & Mean: & $\begin{array}{l}\text { Standard } \\
\text { Dev: }\end{array}$ & $\begin{array}{l}\text { Coef. } \\
\text { Var: }\end{array}$ & $\begin{array}{l}\% \text { Diff } \\
\text { Biot \& } \\
\text { Vesic: }\end{array}$ \\
\hline 10 & 0.25 & 24.24 & 22.51 & 29.09 & 34.14 & 25.72 & 27.138 & 4.600 & 0.169 & 7.369 \\
\hline 10 & 0.5 & 25.12 & 22.91 & 30.47 & 37.03 & 26.28 & 28.363 & 5.569 & 0.196 & 9.185 \\
\hline 10 & 1 & 23.62 & 20.95 & 28.57 & 35.76 & 24.00 & 26.578 & 5.816 & 0.219 & 11.955 \\
\hline 10 & 2 & 18.70 & 16.10 & 22.50 & 29.80 & 18.30 & 21.080 & 5.391 & 0.256 & 14.943 \\
\hline 20 & 0.5 & 25.13 & 22.92 & 30.47 & 37.03 & 26.29 & 28.368 & 5.566 & 0.196 & 9.179 \\
\hline 20 & 1 & 24.04 & 21.58 & 28.77 & 35.80 & 24.43 & 26.922 & 5.597 & 0.208 & 10.794 \\
\hline 20 & 2 & 21.87 & 19.30 & 25.48 & 32.20 & 21.39 & 24.050 & 5.070 & 0.211 & 12.479 \\
\hline 20 & 5 & 16.60 & 14.10 & 18.70 & 24.80 & 15.20 & 17.880 & 4.233 & 0.237 & 16.287 \\
\hline & & & & & & & & & & \\
\hline
\end{tabular}




\begin{tabular}{|c|c|c|c|c|c|c|c|c|c|c|}
30 & 1 & 24.04 & 21.58 & 28.77 & 35.80 & 24.43 & 26.923 & 5.596 & 0.208 & 10.788 \\
\hline 30 & 2 & 21.90 & 19.37 & 25.50 & 32.21 & 21.44 & 24.083 & 5.049 & 0.210 & 12.237 \\
\hline 30 & 5 & 18.27 & 15.71 & 20.35 & 26.21 & 16.79 & 19.466 & 4.153 & 0.213 & 15.050 \\
\hline & & & & & & & & & & \\
\hline 40 & 1 & 24.04 & 21.58 & 28.77 & 35.80 & 24.43 & 26.923 & 5.596 & 0.208 & 10.788 \\
\hline 40 & 2 & 21.90 & 19.38 & 25.50 & 32.21 & 21.44 & 24.085 & 5.048 & 0.210 & 12.229 \\
\hline 40 & 5 & 18.53 & 16.10 & 20.55 & 26.26 & 17.14 & 19.716 & 4.021 & 0.204 & 14.024 \\
\hline 40 & 10 & 15.37 & 12.97 & 16.45 & 21.56 & 13.42 & 15.954 & 3.438 & 0.216 & 16.932 \\
\hline
\end{tabular}

A summary of all the data from the sensitivity analyses is set out in Table 3. Overall, the coefficient of variation between the frequencies predicted by each model varied from $18.4 \%$ to $26.8 \%$ for the loose sand case, and $16.9 \%$ to $25.6 \%$ for the dense sand case. This highlights the sensitivity of the calculated frequency response to the choice of subgrade model when the soil and pile properties are constants. The percentage difference between Biot's model and Vesic's model varied from $7.3 \%$ to $16.7 \%$ for the loose sand case and $7.4 \%$ to $16.9 \%$ for the dense sand case. This large variation would have a significant effect on the frequency response predicted at the various limit states considered in design, since this initial stiffness parameter governs the small-strain behaviour for nonlinear modelling.

In order to highlight the effect of the variation in the predicted natural frequency, a time-domain dynamic response of a pile is undertaken by solving the second-order differential equation shown in Eq. (7) using the Wilson-theta method. The pile with a diameter of $0.25 \mathrm{~m}$ and embedded depth of 10 $\mathrm{m}$ in loose sand is considered. An un-damped time-domain acceleration signal is generated as a result of an excitation input, in this case a short duration impulse force of magnitude equal to $500 \mathrm{~N}$ applied to the transverse degree of freedom at the pile head. The analyses were repeated using the soil stiffness derived for the five subgrade models considered. The results are shown in the time domain in Fig. 6a. From this plot, it is evident that each signal is oscillating at a different frequency and amplitude. The responses in Fig. 6a were analysed with a fast Fourier transform to obtain the frequency response spectra, shown in Fig. 6b. The peak of each plot represents the dominant frequency and should closely approximate the value obtained in the eigenvalue analyses in Table 3 allowing for some signal resolution errors. The significant effect of input stiffness on the natural frequency obtained is illustrated clearly in Fig. $6 \mathrm{~b}$ by the disparity between the frequency peaks for constant soil and pile properties. 

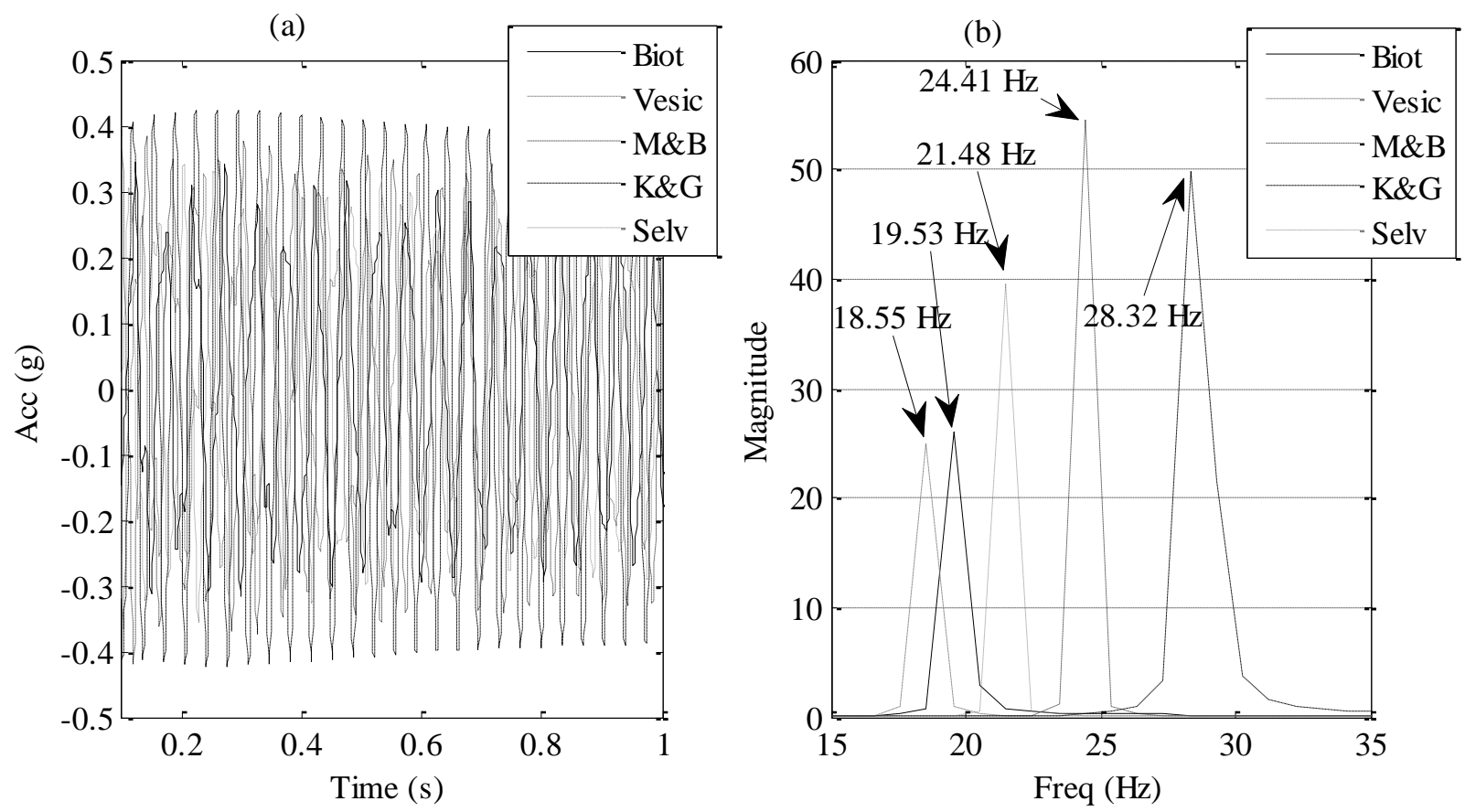

Fig. 6. Dynamic response example - design case 1; (a) Acceleration responses predicted by each model (g); (b) Frequency spectrum of acceleration signals in (a).

The disparity in predicted frequency can be further highlighted by observing the differences in the first mode shapes extracted from the eigenvalue analysis in the models. These mode shapes are plotted for the same design case in Fig. 7, where $0 \mathrm{~m}$ represents the pile base, and a $1 \mathrm{~m}$ stick-up above ground level is considered. The mode shapes correspond to the first mode of vibration and are plotted relative to distance from the pile tip. As can be seen, a difference is observed which matches the response seen in Fig. 6. The difference between the mode shapes shown in Fig. 7 arises directly as a result of the difference in the spring stiffness formulation from each subgrade reaction method. 


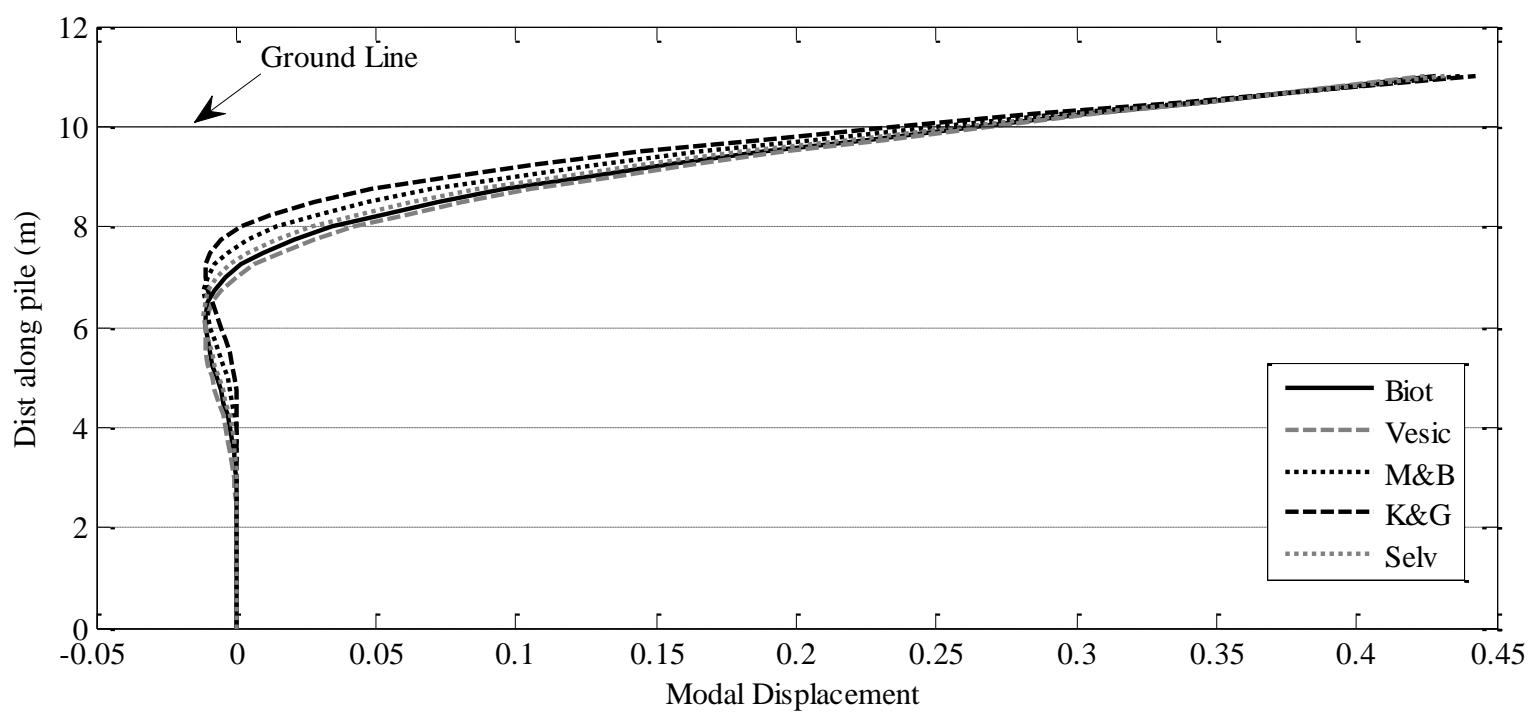

Fig. 7. First mode shapes predicted by implementation of different subgrade reaction theories.

\subsection{Field experiment}

\subsection{Test procedure and site investigation}

In order to examine the effect of pile slenderness (L/D ratio) on the measured and predicted pile response, a field test was undertaken. Two $340 \mathrm{~mm}$ diameter steel open-ended piles were driven to an embedment depth of $7 \mathrm{~m}(\mathrm{~L} / \mathrm{D}=21)$ in dense, over-consolidated sand. The sand around Pile 1 was then excavated (See Fig. 9 for photo of experiment) until the pile embedment depth was $4.5 \mathrm{~m}$ (L/D = 13). A similar excavation process was undertaken for Pile 2 until the pile embedment depth was $3.1 \mathrm{~m}$ $(\mathrm{L} / \mathrm{D}=9)$. An experiment was performed in which three accelerometers were fitted near the pile head of each pile (see Fig. 8) and a modal hammer was used to perform a small-strain vibration test. The natural frequencies obtained in the experiment are compared in this section to numerical predictions obtained using the modelling procedure outlined in section 3.0. 


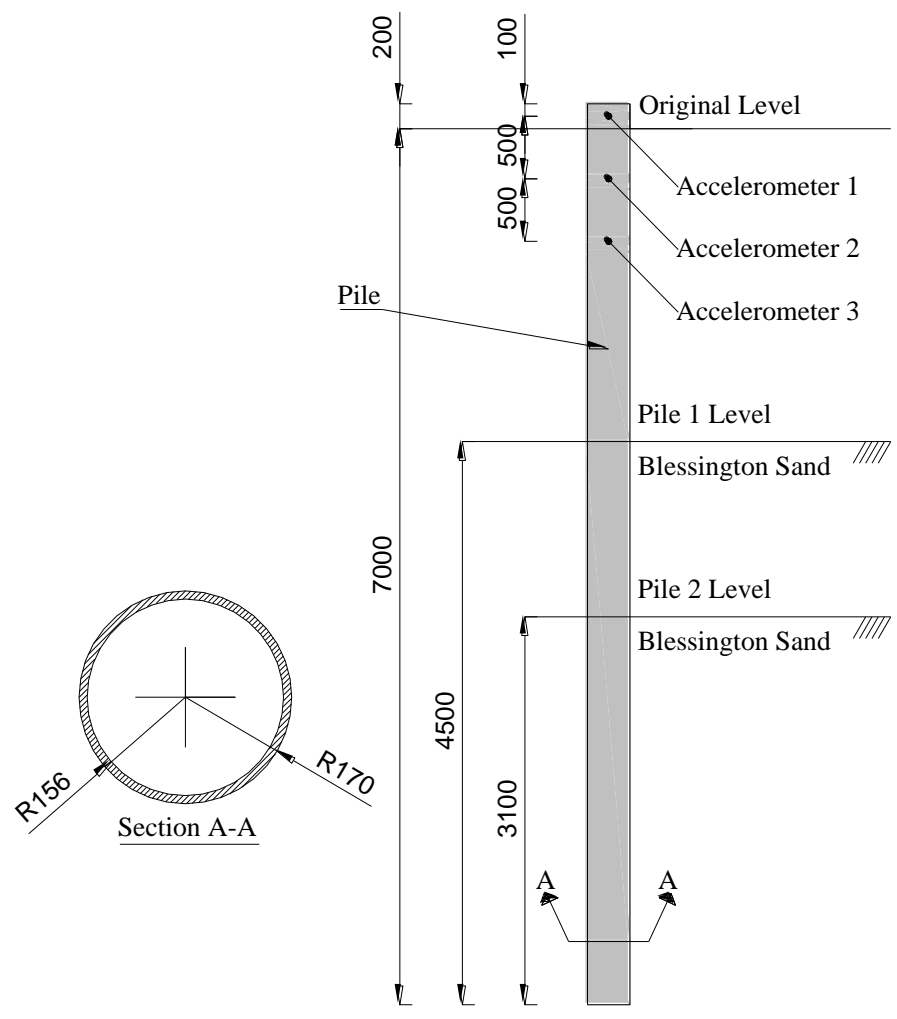

(a)

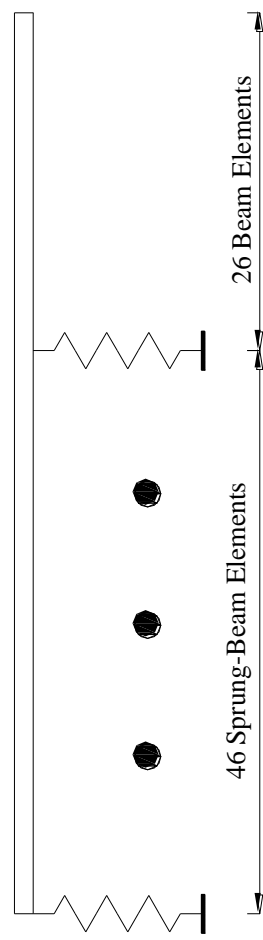

(b)

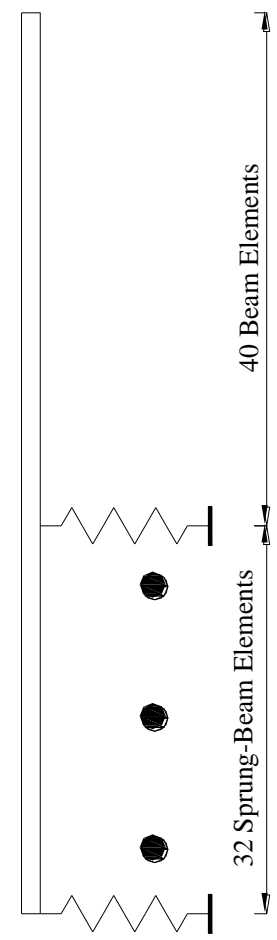

(c)

Fig. 8. Experimental layout; (a) Experimental schematic for Pile $1 \& 2$; (b) Numerical schematic for Pile 1; (c) Numerical schematic for Pile 2. 


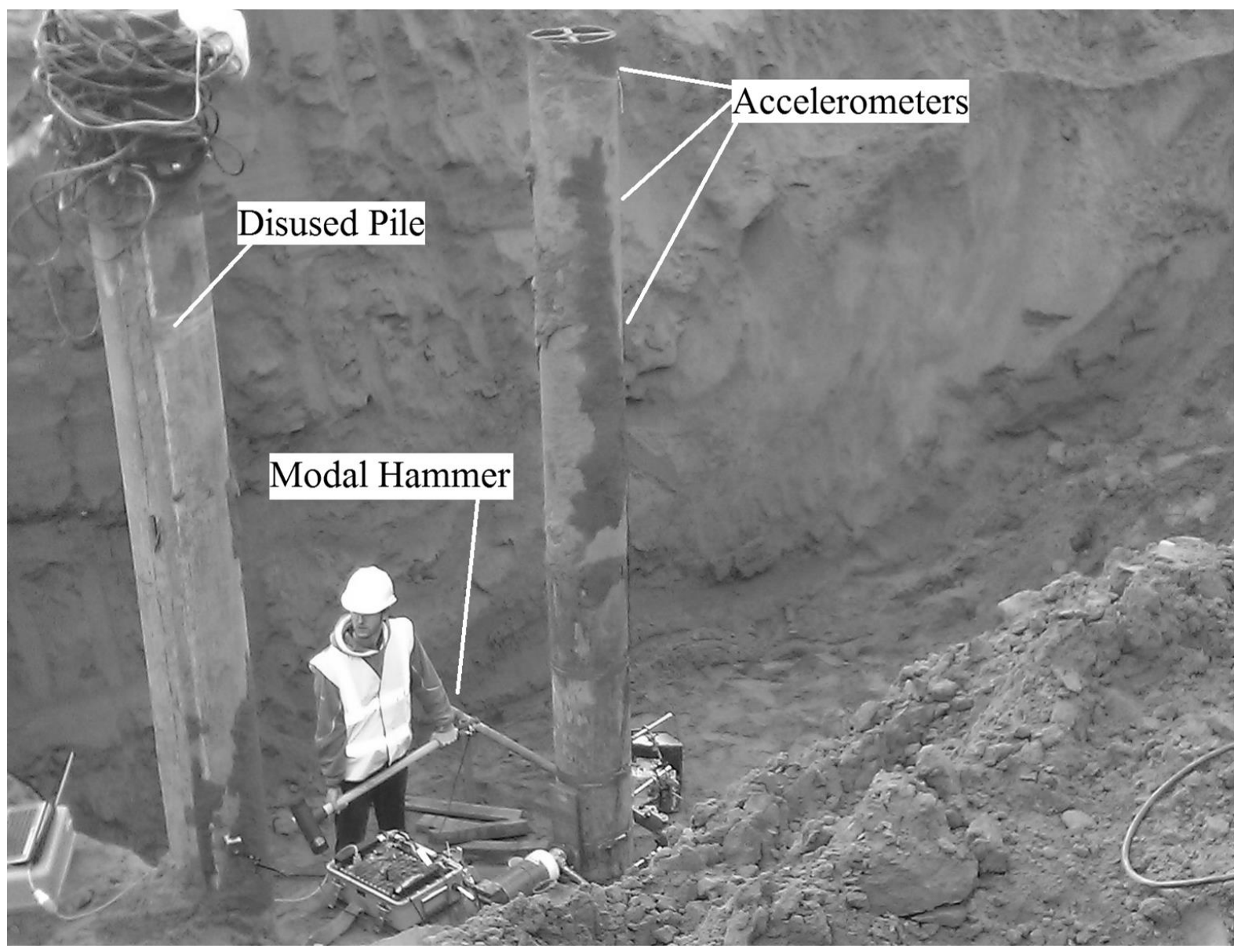

Fig. 9. Layout of experiment - Pile 2.

The field investigation was undertaken at the University College Dublin (UCD) dense sand test bed located near Blessington, southwest of Dublin, Ireland. This test site has been developed over the past eleven years and has been used for a number of model, prototype and full scale foundation experiments [32-35]. A full description of the geotechnical properties of the site can be obtained in $[5,32,36]$. The site is comprised of very dense, fine sand with a relative density between $90 \%$ and $100 \%$. The sand has a bulk density of $2.10 \mathrm{Mg} \mathrm{m}^{-3}$, a unit weight of $19.8 \mathrm{kN} \mathrm{m}^{-3}$ and a constant volume friction angle of $37^{\circ}$. The peak friction angle ranges from $54^{\circ}$ to $40^{\circ}$ over the depth range of interest in this paper. The equilibrium water depth is approximately $13 \mathrm{~m}$ below ground level (bgl). The sand is partially saturated, with the degree of saturation above the water table being between $63 \%$ and $75 \%$. The shear wave velocity profile for the site is shown in Fig. 10a and the derived Young's modulus $\left(\mathrm{E}_{0}\right)$ profile for the site is shown in Fig. 10b. The shear wave velocity profile was obtained using the Multi-channel Analysis of Surface Waves (MASW) method (see [37]). The $\mathrm{E}_{0}$ profile is obtained by first converting the shear wave velocity measurements to the small-strain shear modulus $\left(\mathrm{G}_{0}\right)$ using the relation shown in Eq. (13).

$$
\mathrm{G}_{0}=\rho V_{s}^{2}
$$


where $\rho$ is the soil density $\left(\mathrm{kg} \mathrm{m}^{-3}\right)$. Once the shear modulus profile is obtained, the Young's modulus $\left(\mathrm{E}_{0}\right)$ profile can be derived using the relation shown in Eq. (12). This derived $\mathrm{E}_{0}$ profile is used with each of the subgrade reaction formulations discussed in section 2.0 to ascertain which formulation gives the closest approximation of the system natural frequency at low strain for the given experimental geometries considered.
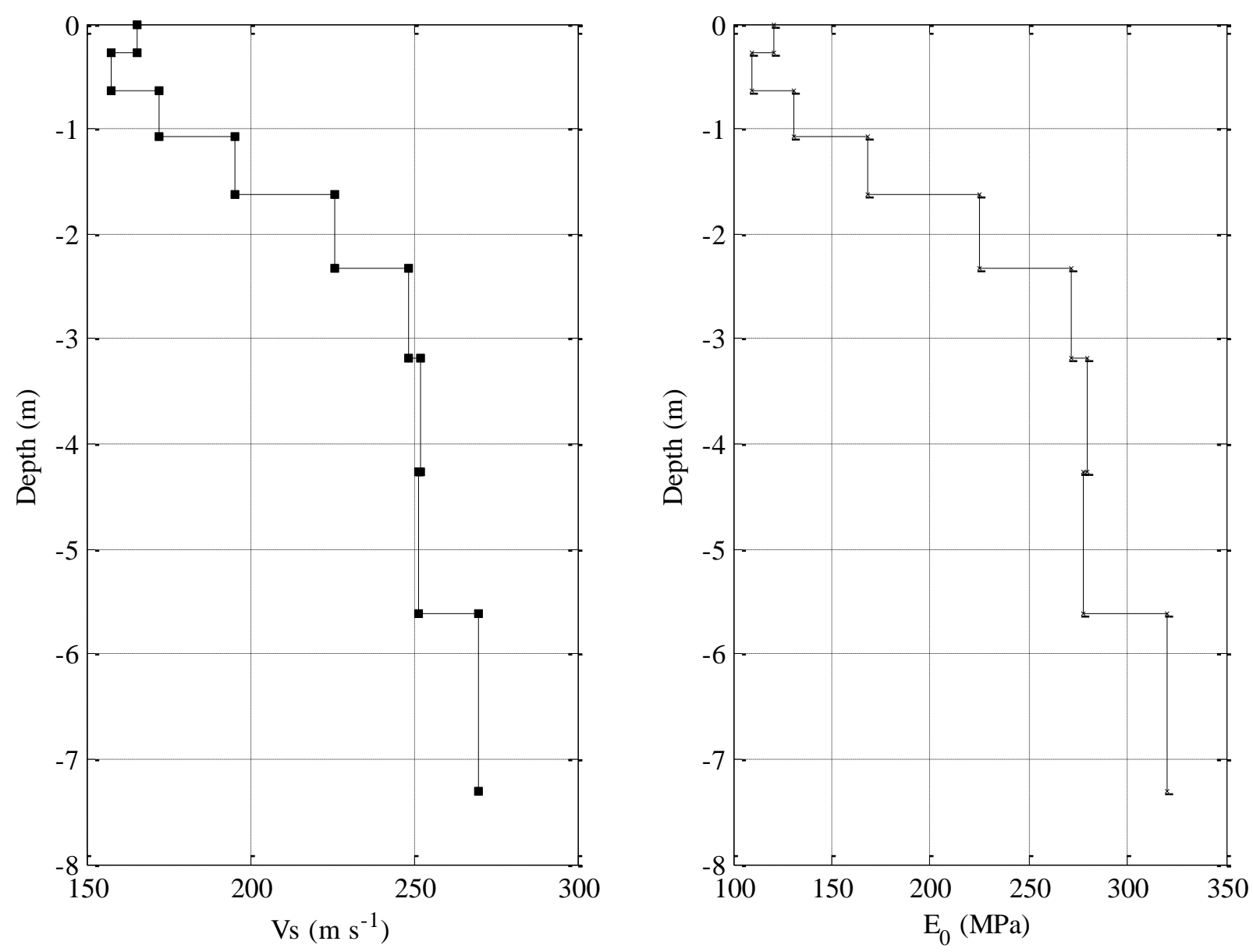

Fig. 10. MASW test results from Blessington test site; (a) Shear wave velocity measurements; (b) Young's modulus $\left(\mathrm{E}_{0}\right)$ profile

\subsection{Experimental frequency response and damping ratios}

The accelerometers placed on the pile were hard-wired into a Campbell Scientific CR9000x Datalogger and programmed to scan at $1000 \mathrm{~Hz}$. This scan rate was adequate to ensure an accurate estimate of the first natural frequency of the system under test.

Both ambient and impact vibration testing were undertaken on each pile to obtain an estimate of the system natural frequency at low strains. The ambient testing regime involved switching on the acquisition system to begin scanning at $1000 \mathrm{~Hz}$ and monitoring the system response for a period of 
five minutes. The input excitation for this testing regime comes from environmental influences such as wind and other sources. The ambient acceleration signals were analysed using two methods. The first method involved passing each individual time-domain acceleration signal from each accelerometer through a fast Fourier transform algorithm implemented in MATLAB. The second method involved analysing all three time-domain accelerometer signals simultaneously using Frequency Domain Decomposition (FDD) [38]. The FDD procedure is an improvement on the classical Fourier transform approach as it is less sensitive to frequency resolution problems and allows for easier estimation of closely spaced modes. The FDD process involves taking the Singular Value Decomposition (SVD) of the spectral matrix and decomposing it into a set of auto-spectral density functions that each correspond to a single degree of freedom (SDOF) system [39]. The method is most effective when the input excitation is broad-banded (white noise) and the structure is lightly damped. Due to the relatively large free length of each pile above the new ground line, this method is ideal for the analysis of the signals. The input ambient excitation is assumed broad-banded.

The impact testing regime involved applying an impulse to each pile using a calibrated modal hammer and measuring the output acceleration response. The hammer used was a 086D50 model manufactured by PCB Piezontronics. This is a large sledgehammer, which was calibrated to excite low frequency resonances (fundamental mode) by fitting a soft impact tip to the heavy impact head. A number of impulses were applied during each testing phase to ensure repeatability of the results. The impact test signals were analysed by developing Frequency Response Functions (FRFs), which show the ratio of the Fourier transform of the measured output $v(t)$ to the Fourier transform of the input stimulus $u(t)[12,40]$. This is shown in Eq. (14). In this instance, the input stimulus is the time history of forces over the impact duration and the output response is the measured acceleration from each accelerometer. A separate FRF is developed for each force-acceleration pair and the results are averaged.

$$
H(\omega)=\frac{V(\omega)}{U(\omega)}
$$

where $\mathrm{V}(\omega)$ is the Fourier transform of the system output and $\mathrm{U}(\omega)$ is the Fourier transform of the system input. An example of an ambient and forced acceleration signal and the resulting frequency response plots for Pile 1 is shown in Fig. 11. 
(a)

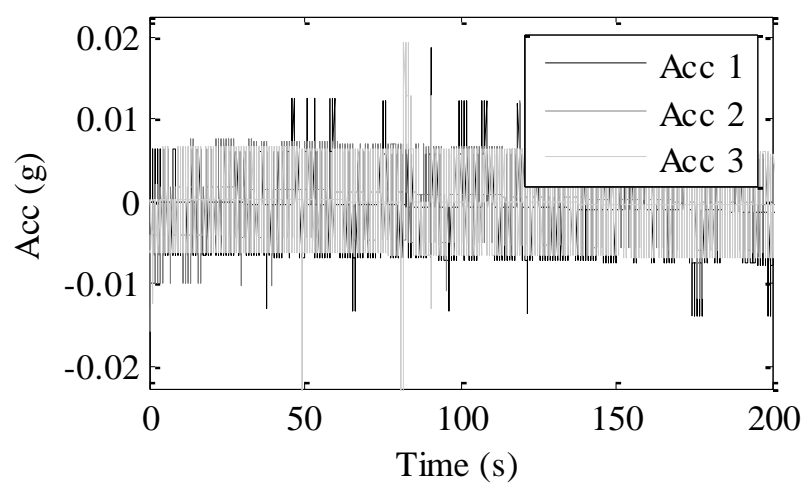

(c)

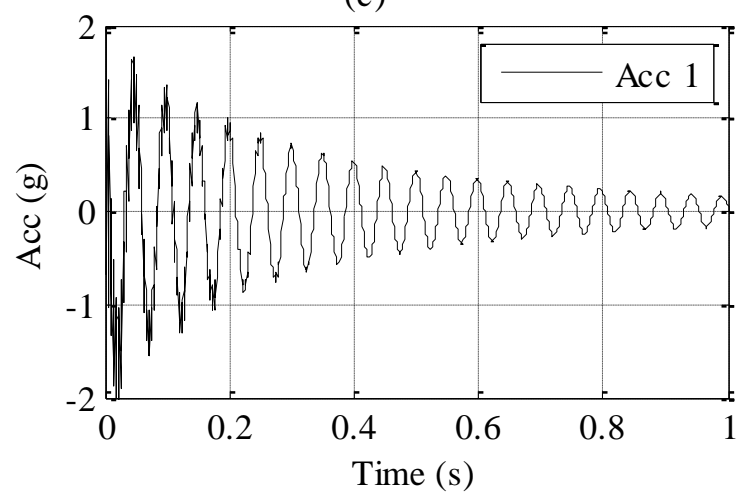

(b)

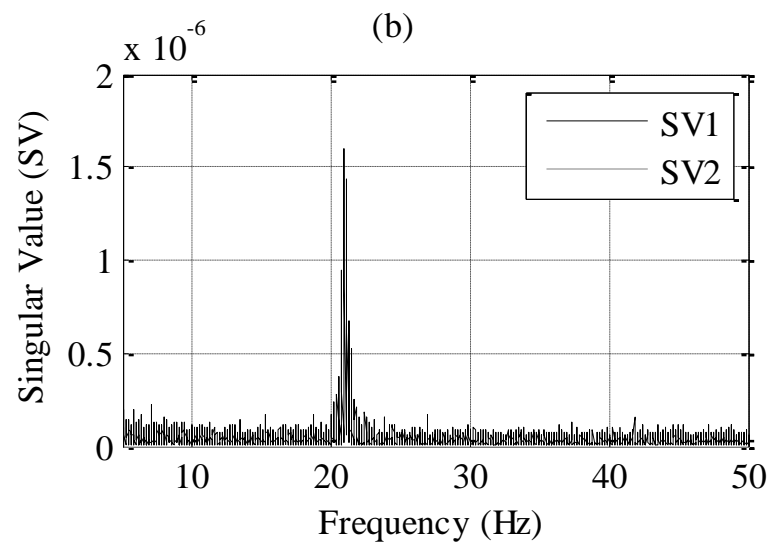

(d)

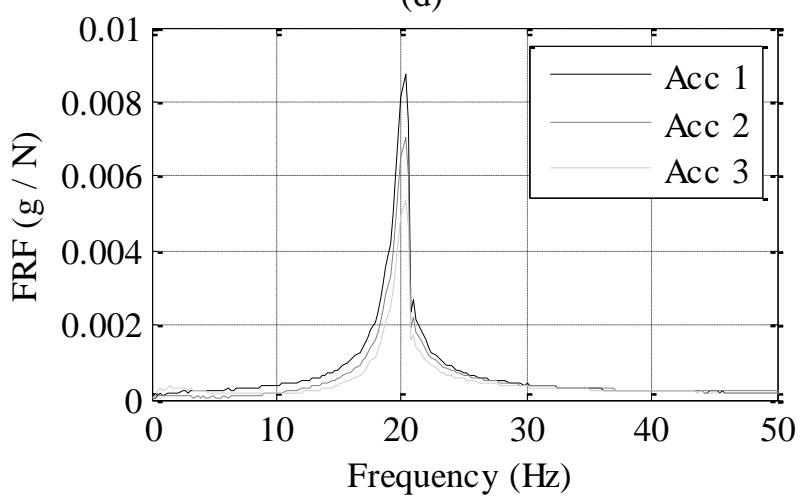

Fig. 11. Example of analysis for Pile 1; (a) Ambient acceleration signals (200 second segment shown); (b) Frequency Domain Decomposition (FDD) of ambient signals shown in (a); (c) Forced acceleration response from top accelerometer (g); (d) FRFs of forced accelerations responses.

Fig. 11a shows a 200 second long sample of the ambient acceleration signal obtained from the vibration testing of Pile 1. Fig.11b shows the frequency response spectrum obtained using the FDD algorithm on all three the signals shown in Fig.11a. Fig.11c shows the acceleration response measured as a result of applying the impact force from the modal hammer. The response shown is from accelerometer 1 (other two accelerations are omitted for clarity) which is at the top of the pile. The impulse force was applied at a distance of $1 \mathrm{~m}$ below the pile head. Fig.11d shows the FRFs developed for the impulse applied to the pile and each of the acceleration responses measured. The results were quite consistent from each accelerometer. The slightly lower natural frequencies measured using the impact response testing relative to the ambient response testing may be as a result of the strain-level dependence of soil stiffness or due to signal resolution issues with the shorter signals. This slight difference is evident between Figs. $11 \mathrm{~b}$ and $11 \mathrm{~d}$ and is shown in Table 4.

Damping was measured from the decay in the acceleration signals resulting from the impact testing. The purpose of measuring the damping ratio for the experimental signals is to allow a direct modelling of the experimental tests in the numerical environment so that the predicted frequencies from the numerical model can be compared directly to the experimental results (i.e. a comparison of damped natural frequencies from the experiment and the model can be made). The measured damping 
ratios can be modelled in the numerical model using the Rayleigh damping approach discussed in section 3.0. The damping ratio for each of the impact vibration tests was measured from the exponential time-domain decay as seen in the signal shown in Fig. 12. There are a number of ways to estimate damping such as logarithmic decrement method [12,20,41,42], half-power bandwidth method $[43,44]$ and curve-fitting, as well as numerous others. In this paper, damping was estimated using a curve fitting technique, whereby an exponential decay function is fit to the oscillation peaks of the time-domain signal in a least-squares sense [41]. By way of a check, the damping ratios were also measured using the logarithmic decrement technique averaged over the number of peaks used for the curve-fitting method. For the exponential curve fitting method, the equation takes the form shown in Eq. (15).

$$
u(t)=u_{0} e^{-\xi \omega_{n} t}=u_{0} e^{-\psi t}
$$

where $u_{0}$ and $\psi$ are the curve-fitting parameters for the exponential function, $\xi$ is the system damping ratio and $\omega_{\mathrm{n}}$ is the un-damped circular frequency $\left(\operatorname{rad~s}^{-1}\right)$. $\xi$ can be estimated using the relation shown in Eq. (16).

$$
\xi=\frac{\psi}{\omega_{n}}=\frac{\psi}{2 \pi f}
$$

where $f$ is the natural cyclic frequency $(\mathrm{Hz})$ of the signal. As with all multi-degree of freedom systems, the time-domain acceleration response will contain contributions from numerous modes as well as from noise [12]. In the first instance, the signal is filtered using a low-pass Butterworth filter to isolate the portion of the signal pertaining to the first natural frequency in bending, which removes the influence of higher modes and noise associated with the impact testing from the signal. Once filtered, an exponential decay function is fitted to the peaks in the time domain using a least squares algorithm by specifying the number of peaks to fit. In this case, a total of 50 peaks were used to obtain an estimate of the damping ratio for the Pile 1 testing and 30 peaks for the Pile 2 testing (due to the lower frequency and hence lower number of peaks available for Pile 2). The first peak is ignored in each signal as this typically arises as a result of the application of the impulse force to the pile.

The filtering and curve-fitting process is shown in Fig. 12. Fig. 12a shows the original and filtered accelerations signals from the top accelerometer of Pile 2 due to the application of an impulse from the modal hammer. From this figure, we can see that the unfiltered signal in grey contains a significant amount of high frequency vibrations, which arise as a result of the application of the impulse force to the pile inducing localized cross-sectional deformation in the vicinity of the impact. Similar examples of this phenomenon can be found in [5,12]. Filtering the signal has the effect of removing the high frequency oscillations at the beginning of the unfiltered signal and exposing the 
signal pertaining to the first natural (bending) frequency of vibration. The filtered signal is shown in heavy black. Fig. 12b illustrates the exponential curve fitting to the filtered signal to estimate the damping ratio. As mentioned, the first peak is ignored as this is generally understood to be as a result of the application of the impulse force [12].

(a)

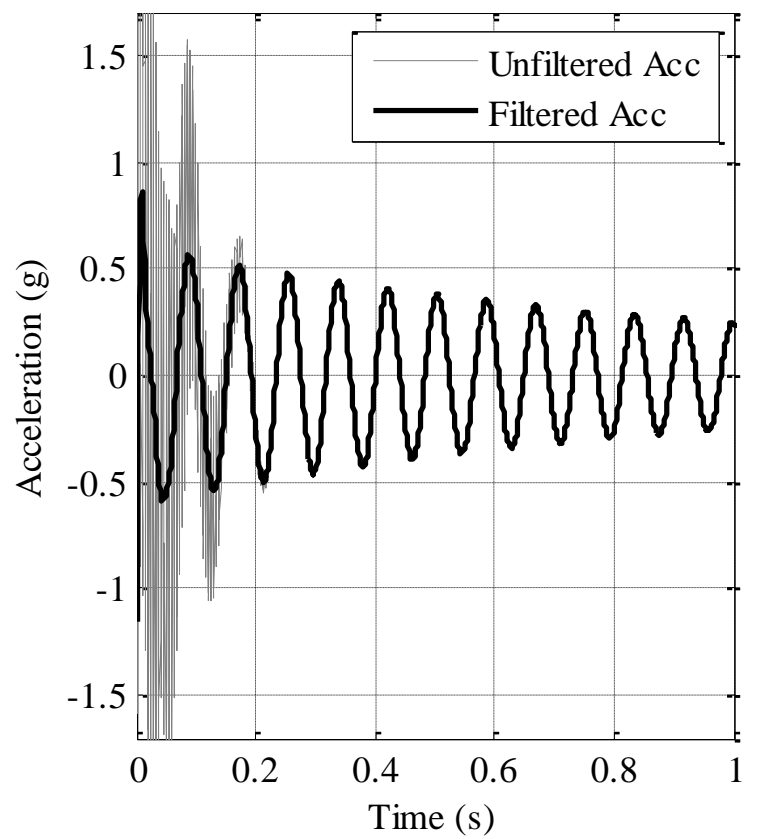

(b)

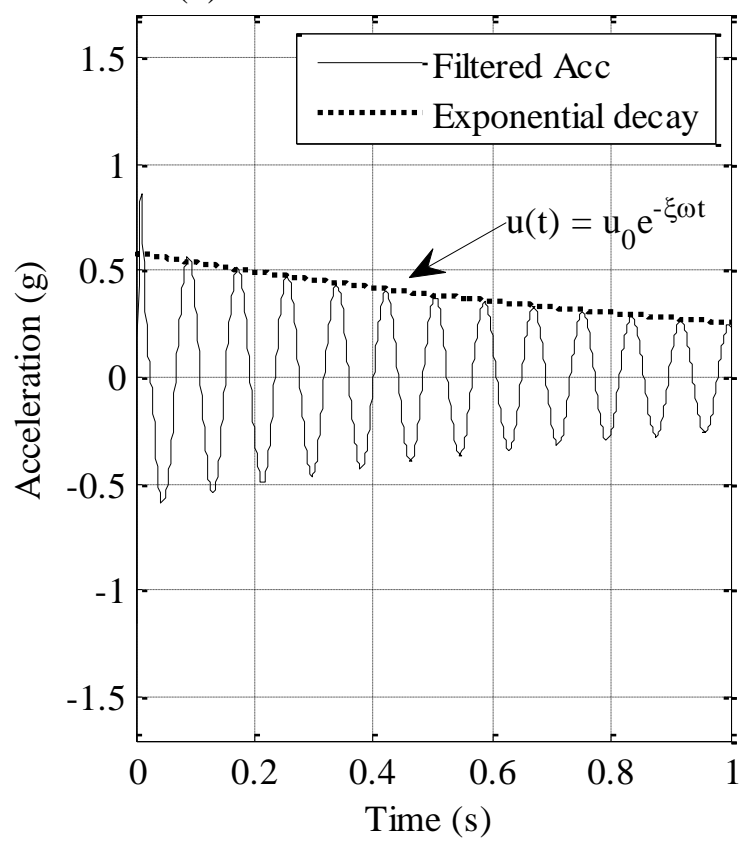

Fig.12. Measurement of damping ratio. (a) Unfiltered and filtered accelerations; (b) Fitting exponential decay function

The results of the experimental analysis of both piles are presented in Table 4. The damping ratios shown are the average values taken over a number of impacts for the top accelerometer located near the pile head for each pile.

Table 4 Experimental Results from Pile Testing.

\begin{tabular}{|l|l|l|}
\hline \multicolumn{3}{|c|}{ Pile 1 - L/D =13 } \\
\hline Method: & $\begin{array}{l}\text { Frequency } \pm \text { Standard } \\
\text { Deviation (Hz): }\end{array}$ & $\begin{array}{l}\text { Damping ratio } \pm \text { Standard } \\
\text { Deviation (\%) }\end{array}$ \\
\hline Ambient (FDD) & \multicolumn{1}{|c|}{21} & $1.8 \pm 0.076$ \\
\hline Forced (FRF) & \multicolumn{1}{|c|}{ Pile 2 - L/D =9 } & - \\
\hline Method: & $\begin{array}{l}\text { Frequency } \pm \text { Standard } \\
\text { Deviation (Hz): }\end{array}$ & $\begin{array}{l}\text { Damping ratio } \pm \text { Standard } \\
\text { Deviation (\%) }\end{array}$ \\
\hline Ambient (FDD) & \multicolumn{1}{|c|}{12.49} & - \\
\hline
\end{tabular}




\begin{tabular}{|l|c|c|}
\hline Forced (FRF) & $12.14 \pm 0.122$ & $1.26 \pm 0.1$ \\
\hline
\end{tabular}

\subsection{Comparison of experimental results with numerical analysis}

In order to compare the experimental results with numerical predictions obtained using the five subgrade reaction stiffness formulations, a direct modelling of the forced vibration test was undertaken for both Pile 1 and Pile 2. The reason behind comparing the forced vibration tests to numerical models instead of comparing the ambient tests is simply because the input excitation for the ambient test is unknown hence modelling this would require modelling a random excitation input. Since a number of impact tests were undertaken on each pile, to facilitate a direct comparison, only the first impact test is modelled for each pile (however, it is noteworthy that the results are similar for each case, see Table 4). The input force measured from the modal hammer for each pile test was modelled as an input to the numerical model and is applied to the lateral degree of freedom closest to the point of application of the force on the real system. For Pile 1, the force is applied $1 \mathrm{~m}$ below the pile head and for Pile 2 the force is applied $2 \mathrm{~m}$ below the pile head. The damping ratio $(\xi)$ measured using the curve-fitting technique described above was modelled in the numerical model using the Rayleigh damping formulation discussed in section 3.0.

The stiffness values derived for Pile 1 using the five subgrade reaction models are shown in Fig. 13, with the individual spring constants highlighted using markers. The stiffness profile is plotted relative to the original ground level (pre-excavation) hence why the depth begins at $-2.5 \mathrm{~m}$ below ground level. From this figure, the disparity in predicted stiffness using each of the five methods is evident once again by the spread of values. 


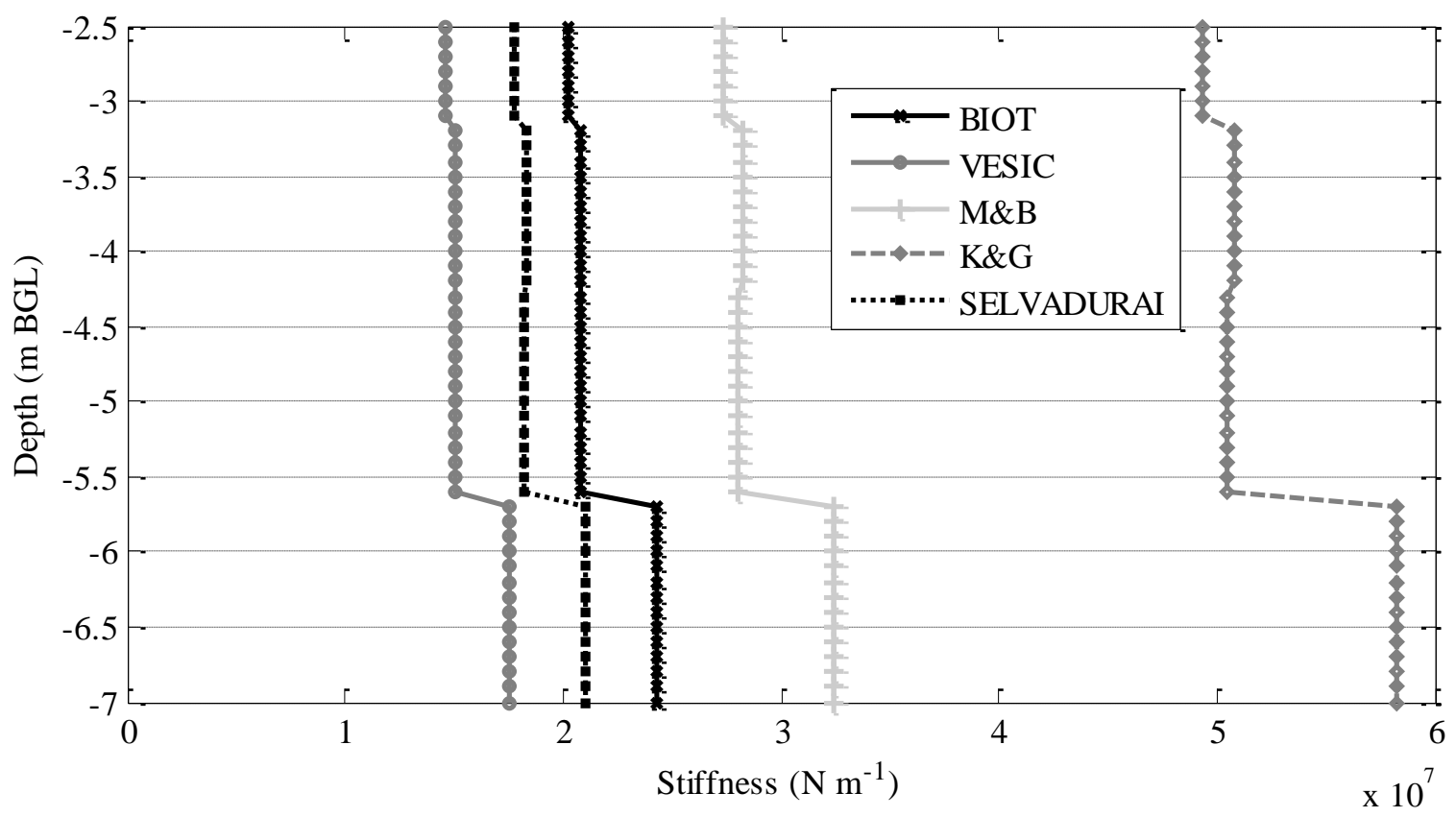

Fig. 13. Stiffness profiles from each subgrade theory for the given pile dimensions for Pile $1\left(\mathrm{~N} \mathrm{~m}^{-1}\right)$.

Both the experimental results and numerical predictions for the impact test on Pile 1 are shown in Fig. 14. Each of the five subgrade models is shown. Fig. 14a shows the experimental and predicted timedomain acceleration decays for each of the subgrade stiffness formulations for the first impact test on Pile 1. These are arranged in a column, with each row showing the experimental results and the relevant numerical prediction. The signals from Fig. 14a were each analysed along with the force input to generate Frequency Response Functions (FRF) to obtain the frequency content as presented in Fig. 14b (see Eq. (14)). This figure shows that the frequencies predicted by each model employing the different subgrade reaction stiffnesses each overestimate the measured system response to varying degrees. The percentage difference between the experimental results and those predicted by each numerical model is presented in Table 5. 
(a)
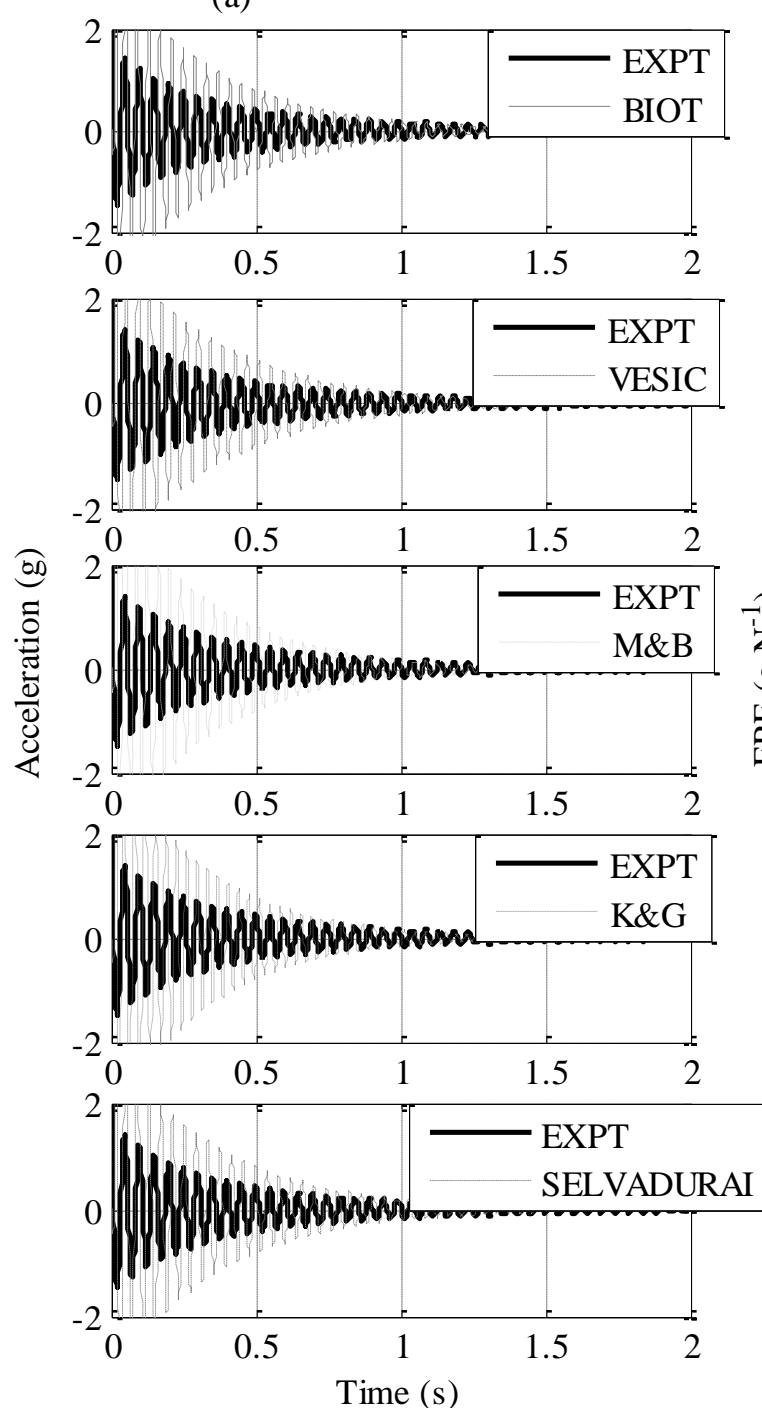

(b)
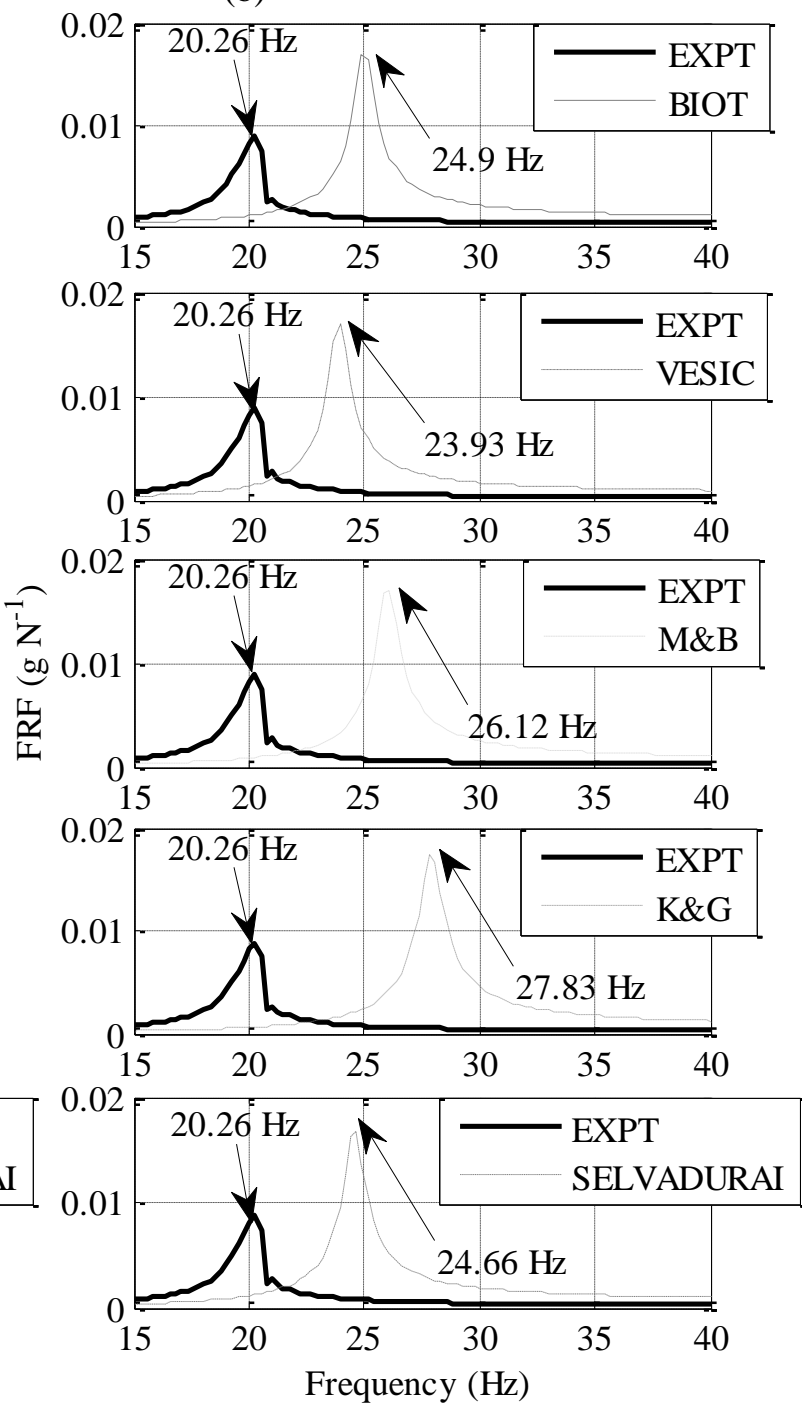

Fig. 14. Comparison of experimental and numerical results for Pile 1 impact test 1. (a) Time-domain acceleration signals from the experiment and each of the five numerical models, (b) Frequency response functions of experiment and each of the five numerical models.

Table 5 Comparison of experimental results and numerical predictions.

\begin{tabular}{|l|c|c|c|}
\hline \multicolumn{4}{|c|}{ Pile I - L/D = 13 } \\
\hline Method & $\begin{array}{l}\text { Numerical } \\
\text { Frequency (Hz) }\end{array}$ & Impact Experimental (Hz) & \% Difference \\
\hline BIOT & 24.9 & 20.26 & 20.5 \\
\hline VESIC & 23.93 & 20.26 & 16.6 \\
\hline M\&B & 26.12 & 20.26 & 25.3 \\
\hline K\&G & 27.83 & 20.26 & 31.5 \\
\hline SELVADURAI & 24.66 & 20.26 & 19.6 \\
\hline
\end{tabular}




\begin{tabular}{|l|c|c|c|}
\hline \multicolumn{4}{|c|}{ Pile 2 - L/D = 9 } \\
\hline Method & $\begin{array}{l}\text { Numerical } \\
\text { Frequency (Hz) }\end{array}$ & Impact Experimental (Hz) & \% Difference \\
\hline BIOT & 13.18 & 12.21 & 7.6 \\
\hline VESIC & 12.70 & 12.21 & 3.9 \\
\hline M\&B & 13.43 & 12.21 & 9.5 \\
\hline K\&G & 14.16 & 12.21 & 14.8 \\
\hline SELVADURAI & 12.94 & 12.21 & 5.8 \\
\hline
\end{tabular}

As indicated in Fig. 14 and Table 5, all models overestimate the frequency (or stiffness) of both piles, with the largest over-prediction occurring for the pile with the highest L/D ratio. The numerical models also slightly over-estimate the magnitude of the acceleration in the time-domain, as can be seen in Fig. 14a. For Pile 2 (with an L/D ratio of 9), the models predicted a reasonable estimate of the frequency with over-estimates in the range $3.9 \%$ to $14.8 \%$, whereas for Pile 1 (with a L/D ratio of 13) the over-estimation ranged from $16.6 \%$ to $31.5 \%$.

One possible explanation for the over-prediction in the case of Pile 1 may be the fact that this pile had a small cap located inside the head, the mass of which was not factored into the numerical model. Another viable reason for the over prediction of each model may lie with the effect of pile installation (driving) on the in-situ $\mathrm{G}_{0}$, an effect which was ignored in this study. While the experimental arrangement of inducing very small strains into the soil mass by impacting the pile with the modal hammer may justify the use of $\mathrm{G}_{0}$, the effect of pile installation inducing large strains in the shear zone around the pile may change significantly the operational shear modulus (G) of the sand. The difficulty with choosing an appropriate operational $\mathrm{G}$ value is that this parameter typically decreases with strain and increases with stress. The large strains that arise during the installation of the pile may reduce the operational $\mathrm{G}$ value in the vicinity of the pile. However, this effect may be counterbalanced by an increase in the far-field confining stiffness, an effect which arises due to the high stresses and over-consolidation that occurs as the pile tip passes during driving. In addition to these phenomena, aging has been shown to increase the stiffness characteristics of a soil mass, which may offset the effects of installation. As a result, the $\mathrm{G}_{0}$ was chosen for the analysis in this paper due to the difficulty in estimating an operational $\mathrm{G}$ value, which may have given improved results.

It is noteworthy that there may also exist some errors in the estimation of the $G_{0}$ profile for the test site from the multi-channel analysis of surface waves method. Any errors in the estimation of the $\mathrm{G}_{0}$ profile will have knock-on effects for the comparison of the experimental and numerical predictions, particularly in the case of Pile 2 where the L/D ratio was obtained by reducing the depth of soil surrounding the pile to a greater degree than for Pile 1 . Errors in the assumed $G_{0}$ profile may 
contribute for some of the disparities evident between the experimental results and numerical model predictions.

Under the assumptions made in this paper, for both piles, Vesic's model provided the closest approximation to the experimental measurements.

\subsection{Conclusions}

Dynamic soil-structure interaction covers a broad range of load states from small-strain vibrations to large-strain cyclic loading. The difficulty with modelling large-strain dynamic response of piles stems from the variation in the parameters required to model the nonlinear inelastic load-displacement response and associated cyclic degradation that occurs. In this paper, variation in the formulations for the initial (small-strain) stiffness of pile-soil systems is explored. A range of subgrade reaction theories are available with which to estimate the initial dynamic stiffness of piles founded in sand. In this paper, a sensitivity analysis was undertaken to establish the coefficient of variation between the frequency responses predicted using different stiffness formulations for a range of pile diameters and depths of embedment. The primary focus of the analysis was to establish the percentage difference between models proposed by Vesic and Biot, which were derived specifically for the case of infinite beams resting on elastic foundations. This analysis was undertaken by developing a numerical FE model using MATLAB, employing a Winkler spring-beam hypothesis. Secondly, a field investigation to obtain the frequency and damping response of two piles with different $\mathrm{L} / \mathrm{D}$ ratios was undertaken at a dense sand test bed site. The pile response was compared to numerical models employing the site specific stiffness obtained from a geophysical investigation of the site and utilizing the different subgrade reaction models to develop spring stiffness coefficients. In the models, the force from the modal hammer and the damping ratios measured in the experiments were inputted into the numerical model so that a direct comparison of damped natural frequencies could be undertaken for each stiffness formulation. It was found that the Vesic model provided the closest approximation to the experimental responses for the given geometries and soil conditions considered in the experiments.

Further work would include an analysis of piles with different diameters founded in different sand deposits to ascertain if there would be any noticeable change in the models predicting the closest fit. It is also recommended to vary the L/D ratios by way of changing the pile diameter in lieu of changing the depth of soil surrounding the pile, as any errors in the estimation of soil stiffness may be mitigated by ensuring a longer depth of embedment for experimental tests. The further development of the models would consider the range of other parameters required to model the nonlinear dynamic response and assess their performance against experimental measurements at larger strains. The current analysis only considers one pile diameter with two different L/D ratios. 
The research may be useful in the ongoing development of offshore wind turbine foundation design where the dynamic response is paramount to the safe operation and lifetime of these structures.

\section{Acknowledgements}

The authors would like to acknowledge the support of the Earth and Natural Sciences (ENS) Doctoral Studies Programme, funded by the Higher Education Authority (HEA) through the Programme for Research at Third Level Institutions, Cycle 5 (PRTLI-5), co-funded by the European Regional Development Fund (ERDF). The $2^{\text {nd }}$ author was part funded by the EU FP7 SMART RAIL project No. 285683.

\section{References:}

[1] Doebling S, Farrar C. Damage identification and health monitoring of structural and mechanical systems from changes in their vibration characteristics: a literature review. 1996.

[2] Tempel J Van Der, Molenaar D. Wind Turbine Structural Dynamics - A Review of the Principles for Modern Power Generation , Onshore and Offshore. Wind Eng 2002;26:211-20.

[3] Det Norske Veritas. DNV Offshore Standard DNV-OS-J101 Design of Offshore Wind Turbine Structures. 2007.

[4] API. RP2A: Recommended practice for planning, designing and constructing offshore platforms - Working stress design. Washington, DC: 2007.

[5] Prendergast LJ, Hester D, Gavin K, O'Sullivan JJ. An investigation of the changes in the natural frequency of a pile affected by scour. J Sound Vib 2013;332:6685-702.

[6] Ju SH. Determination of scoured bridge natural frequencies with soil-structure interaction. Soil Dyn Earthq Eng 2013;55:247-54.

[7] Foti S, Sabia D. Influence of Foundation Scour on the Dynamic Response of an Existing Bridge. J Bridg Eng 2011;16:295-304.

[8] Kampitsis AE, Sapountzakis EJ, Giannakos SK, Gerolymos N a. Seismic soil-pile-structure kinematic and inertial interaction-A new beam approach. Soil Dyn Earthq Eng 2013;55:21124.

[9] Winkler E. Theory of elasticity and strength. Dominicus Prague: 1867.

[10] Dutta SC, Roy R. A critical review on idealization and modeling for interaction among soilfoundation-structure system. Comput Struct 2002;80:1579-94. 
[11] Allotey N, El Naggar MH. Generalized dynamic Winkler model for nonlinear soil-structure interaction analysis. Can Geotech J 2008;45:560-73.

[12] Dezi F, Gara F, Roia D. Dynamic response of a near-shore pile to lateral impact load. Soil Dyn Earthq Eng 2012;40:34-47.

[13] Boulanger RW, Curras CJ, Kutter BL, Wilson DW, Abghari A. Seismic soil-pile-structure interaction experiments and analysis. J Geotech Geoenvironmental Eng 1999;125:750-9.

[14] Nogami T, Otani J, Konagai K, Chen H. Nonlinear Soil-Pile Interaction Model for Dynamic Lateral Motion. J Geotech Eng 1992;118:89-106.

[15] Love AEH. The mathemathical theory of elasticity. University Press, Cambridge; 1927.

[16] Matlock H. Correlations for design of laterally loaded piles in soft clay. Offshore Technol. Civ. Eng., 1970, p. 577-94.

[17] Vesic AB. Bending of beams resting on isotropic elastic solid. J Soil Mech Found Eng 1961;87:35-53.

[18] Biot MA. Bending of an infinite beam on an elastic foundation. J Appl Mech 1937;59:A1-7.

[19] Daloglu AT, Vallabhan CVG. Values of k for Slab on Winkler Foundation. J Geotech Geoenvironmental Eng 2000;126:463-71.

[20] Ashford SA, Juirnarongrit T. Evaluation of Pile Diameter Effect on Initial Modulus of Subgrade Reaction. Geotech Geoenvironmental Eng 2003;129:234-42.

[21] Bowles JE. Foundation analysis and design. 4th ed. New York, 1004: McGraw-Hill; 1988.

[22] Okeagu B, Abdel-Sayed G. Coefficients of Soil Reaction for Buried Flexible Conduits. J Geotech Eng 1984;110:908-22.

[23] Sadrekarimi J, Akbarzad M. Comparative Study of Methods of Determination of Coefficient of Subgrade Reaction. Electron J Geotech Eng 2009;14.

[24] Elachachi SM, Breysse D, Houy L. Longitudinal variability of soils and structural response of sewer networks. Comput Geotech 2004;31:625-41.

[25] Kwon YW, Bang H. The Finite Element Method using MATLAB. Boca Raton, FL: CRC Press, Inc.; 2000. 
[26] Tedesco JW, McDougal WG, Allen Ross C. Structural Dynamics: Theory and Applications. 1999.

[27] Dukkipati RV. Matlab for Mechanical Engineers. New Age Science; 2009.

[28] Fugro. Guide for Estimating Soil Type and Characteristics using Cone Penetration Testing. Cone Penetration Tests 2011.

[29] Lunne T, Christopherson HP. Interpretation of Cone Penetrometer Data for Offshore Sands. Offshore Technol. Conf. OTC4464, Houston, Texas: 1983.

[30] Jardine RJ, Chow FC, Overy RF, Standing J. ICP Design Methods for Driven Piles in Sands and Clays. London: 2005.

[31] Baldi G, Belottini R, Ghionna VN, Jamiokowski NI, Lo Presti DCF. Modulus of Sands from CPTs and DMTs. Proc. 12th ICSMFE Vol. 1, 1989, p. 165-70.

[32] Gavin KG, Lehane BM. Base Load-Displacement Response of Piles in Sand. Can Geotech J 2007;44:1053-63.

[33] Gavin KG, O'Kelly BC. Effect of friction fatigue on pile capacity in dense sand. J Geotech Geoenvironmental Eng 2007;133:63-71.

[34] Igoe D, Gavin K, O'Kelly B. The shaft capacity of pipe piles in sand. J Geotech Geoenvironmental Eng 2011;137:903-12.

[35] Gavin KG, Tolooiyan A. An Investigation of correlation factors linking footing resistance on sand with cone penetration results. Comput Geotech 2012;46:84-92.

[36] Gavin K, Adekunte A, O'Kelly B. A field investigation of vertical footing response on sand. Proc ICE, Geotech Eng 2009;162:257-67.

[37] Donohue S, Long M, Gavin K, O’Connor P. Shear Wave Stiffness of Irish Glacial Till. Int. Conf. Site Characterisation I, Porto, Portugal: 2004, p. 459-66.

[38] Brincker R, Zhang L, Andersen P. Modal identification of output-only systems using frequency domain decomposition. Smart Mater Struct 2001;10:441-5.

[39] Brincker R, Zhang L, Andersen P. Modal Identification from Ambient Responses using Frequency Domain Decomposition. Proc. 18th Int. Modal Anal. Conf., 2000.

[40] Elsaid A, Seracino R. Rapid assessment of foundation scour using the dynamic features of bridge superstructure. Constr Build Mater 2014;50:42-9. 
[41] Gutenbrunner G, Savov K, Wenzel H. Sensitivity Studies on Damping Estimation. Proc. Second Int. Conf. Exp. Vib. Anal. Civ. Eng. Struct., Porto, Portugal: 2007.

[42] Chopra AK. Dynamics of Structures. A Primer. Earthquake Engineering Research Institute; 1981.

[43] Tsai P, Feng Z, Lin S. A wavelet based method for estimating the damping ratio in statnamic pile load tests. Comput Geotech 2011;38:205-16.

[44] Sohn H, Farra CR, Hemez F, Shunk D, Stinemates D, Nadler B, et al. A Review of Structural Health Monitoring Literature : 1996 - 2001. 2004. 